\title{
A Pharmacological Update of Ellagic Acid
}

\author{
Authors \\ José-Luis Ríos ${ }^{1}$, Rosa M. Giner ${ }^{1}$, Marta Marín ${ }^{2}$, M. Carmen Recio ${ }^{1}$ \\ Affiliations \\ 1 Departament de Farmacologia, Facultat de Farmàcia, \\ Universitat de València, Burjassot, Spain \\ 2 Departamento de Farmacia, Facultad de Ciencias de la \\ Salud, Universidad Cardenal Herrera-CEU, CEU Univer- \\ sities, Alfara del Patriarca, Valencia, Spain \\ Key words \\ ellagic acid, metabolic syndrome, neuroprotection, \\ hepatoprotection, cardiovascular effects, cancer \\ received March 13, 2018 \\ revised April 27, 2018 \\ accepted May 17, 2018 \\ Bibliography \\ DOI https://doi.org/10.1055/a-0633-9492 \\ Published online May 30, 2018 | Planta Med 2018; 84: 1068- \\ 1093 @ Georg Thieme Verlag KG Stuttgart · New York । \\ ISSN 0032-0943 \\ Correspondence \\ Prof. José Luis Ríos \\ Departament de Farmacologia, Facultat de Farmàcia, \\ Universitat de València \\ Av. Vicent Andrés Estellés s/n., 46100 Burjassot, Spain \\ Phone: + 34963544973 , Fax: + 34963544943 \\ riosj@@uv.es

\section{ABSTRACT} \\ Ellagic acid is a common metabolite present in many medici- \\ nal plants and vegetables. It is present either in free form or as \\ part of more complex molecules (ellagitannins), which can be \\ metabolized to liberate ellagic acid and several of its metabo- \\ lites, including urolithins. While ellagic acid's antioxidant \\ properties are doubtless responsible for many of its pharma- \\ cological activities, other mechanisms have also been impli- \\ cated in its various effects, including its ability to reduce the \\ lipidemic profile and lipid metabolism, alter pro-inflammatory \\ mediators (tumor necrosis factor- $\alpha$, interleukin- $1 \beta$, interleu- \\ kin-6), and decrease the activity of nuclear factor- $\kappa$ B while in- \\ creasing nuclear factor erythroid 2-related factor 2 expres- \\ sion. These events play an important role in ellagic acid's \\ anti-atherogenic, anti-inflammatory, and neuroprotective ef- \\ fects. Several of these activities, together with the effect of \\ ellagic acid on insulin, glycogen, phosphatases, aldose reduc- \\ tase, sorbitol accumulation, advanced glycation end-product \\ formation, and resistin secretion, may explain its effects on \\ metabolic syndrome and diabetes. In addition, results from \\ recent research have increased the interest in ellagic acid, \\ both as a potential protective agent of the liver and skin and \\ as a potential anticancer agent, due to the specific mecha- \\ nisms affecting cell proliferation, apoptosis, DNA damage, \\ and angiogenesis and its aforementioned anti-inflammatory \\ properties. Taken together, these effects make ellagic acid a \\ highly interesting compound that may contribute to different \\ aspects of health; however, more studies are needed, espe- \\ cially on the compound's pharmacokinetic profile. In this re- \\ view, we selected papers published from 2005 to the present.
}

\section{Introduction}

Ellagic acid ( $\vee$ Fig. 1 ) is a chromene-dione derivative (2,3,7,8-tetrahydroxy-chromeno[5,4,3-cde]chromene-5,10-dione; $\mathrm{C}_{14} \mathrm{H}_{6} \mathrm{O}_{8}$; $\mathrm{mw}: 302.194 \mathrm{~g} / \mathrm{mol}$ ) [1] possessing a hydrophilic moiety with four hydroxyl groups and two lactones, along with a lipophilic moiety with two hydrocarbon rings. This endows ellagic acid with the capacity both to accept electrons from different substrates as well as to participate in antioxidant redox reactions [2,3]. Ellagic acid can present as cream-colored needles or as a yellow powder with a water solubility of less than $1 \mathrm{mg} / \mathrm{mL}$ at $21^{\circ} \mathrm{C}$ [4]; it is an odorless [4], weak acid that is incompatible with strong reducing agents. It produces an exothermic reaction through the acid-base reaction and is easily sulfonated and nitrated by the corresponding acids [5].
Ellagic acid is present in many fruits (pomegranates, persimmons, raspberries, black raspberries, wild strawberries, peaches, plums), seeds (walnuts, almonds), and vegetables [6]. It can be present in free form or as derivatives, principally as complex polymers called ellagitannins, which can be hydrolyzed by the action of physiological pH and gut microbiota, thus increasing plasma levels of the acid after the ingestion of fruits and vegetables [7]. The actual content of ellagic acid varies from plant to plant, with different concentrations being described depending on the source. Raspberries (fruit of Rubus idaeus L., Rosaceae) probably contain the highest concentration, with values (expressed with respect to fresh weight) ranging from $1900 \mathrm{mg} / 100 \mathrm{~g}$ (yellow raspberries) to $270 \mathrm{mg} / 100 \mathrm{~g}$ (wild raspberries), depending on the sample analyzed. Other species from the same genus also have 


\begin{tabular}{|c|c|}
\hline \multicolumn{2}{|c|}{ ABBREVIATIONS } \\
\hline ABCA1 & ATP-binding cassette transporter-1 \\
\hline AGE & advanced glycation end-products \\
\hline Akt & protein kinase B \\
\hline AP-1 & activator protein-1 \\
\hline Bax & Bcl-2-associated $\mathrm{X}$ protein \\
\hline $\mathrm{Bcl}-2$ & B-cell lymphoma 2 \\
\hline Cdk & cyclin-dependent kinase \\
\hline C/EBP & $\begin{array}{l}\text { cytosine-cytosine-adenine-adenine-thymine } \\
\text { enhancer-binding protein }\end{array}$ \\
\hline CHOP & C/EBP homologous protein \\
\hline $\operatorname{cox}$ & cyclooxygenase \\
\hline CYP & cytochrome P450 \\
\hline DR & death receptor \\
\hline ERK1/2 & extracellular signal-regulated kinase $1 / 2$ \\
\hline HbA1c & glycosylated hemoglobin \\
\hline HDL & high-density lipoprotein \\
\hline HO & heme oxygenase \\
\hline ICAM & intercellular adhesion molecule \\
\hline IкB & inhibitor of kappa B \\
\hline IKK & IKB kinase \\
\hline IL & interleukin \\
\hline IGFBP7 & insulin-like growth factor-binding protein 7 \\
\hline i. p. & intraperitoneal \\
\hline JNK & c-Jun N-terminal kinase \\
\hline LDL & low-density lipoprotein \\
\hline L-NAME & $\mathrm{N} \omega$-Nitro-L-arginine methyl ester hydrochloride \\
\hline LXR & liver $\mathrm{X}$ receptor \\
\hline MAO-B & monoamine oxidase B \\
\hline MAPK & mitogen-activated protein kinase \\
\hline MCP-1 & monocyte chemoattractant protein-1 \\
\hline MIF & migration inhibitory factor \\
\hline MMP & matrix metalloproteinase \\
\hline mPGEs-1 & microsomal prostaglandin E synthase-1 \\
\hline mTOR & mammalian target of rapamycin \\
\hline NF- $\kappa \mathrm{B}$ & nuclear factor- $\kappa \mathrm{B}$ \\
\hline NO & nitric oxide \\
\hline Nrf2 & nuclear factor erythroid 2-related factor 2 \\
\hline p-38 & p38 mitogen-activated protein kinase \\
\hline p-p38 & $\begin{array}{l}\text { phosphorylated-p38 mitogen-activated protein } \\
\text { kinase }\end{array}$ \\
\hline PDGFR- $\beta$ & platelet-derived growth factor receptor- $\beta$ \\
\hline PI3K & phosphoinositide 3-kinase \\
\hline p.o. & pero os, orally \\
\hline PPAR & peroxisome proliferator-activated receptor \\
\hline ROS & reactive oxygen species \\
\hline s.c. & subcutaneous \\
\hline SRB1 & scavenger receptor class B1 \\
\hline STAT3 & signal transducer and activator of transcription 3 \\
\hline TGF- $\beta$ & transforming growth factor- $\beta$ \\
\hline TLR & toll-like receptor \\
\hline TNF- $\alpha$ & tumor necrosis factor- $\alpha$ \\
\hline VCAM & vascular cell adhesion molecule \\
\hline VLDL & very low-density lipoprotein \\
\hline VEGF & vascular endothelial growth factor \\
\hline
\end{tabular}

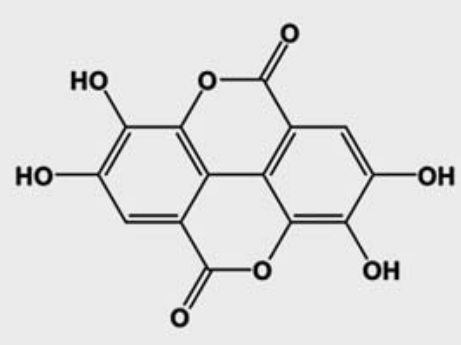

- Fig. 1 Chemical structure of ellagic acid.

high ellagic acid content; these include cloudberries (Rubus chamaemorus L.), blackberries (Rubus sp.), and strawberries (Fragaria $\times$ ananassa [Duchesne ex Weston] Duchesne ex Rozier, Rosaceae). Seeds, such as pecans (Carya illinoinensis [Wangenh.] K.Koch, Juglandaceae) and walnuts (Juglans regia L., Juglandaceae), and beverages such as cognac and oak-aged red wine obtained from grapes (Vitis vinifera L., Vitaceae) also present relevant levels [7]. Other fruits with high levels of ellagic acid are pomegranates (Punica granatum L., Lythraceae), persimmons (Diospyros kaki L.f., Ebenaceae), peaches (Prunus persica [L.] Batsch, Rosaceae), and plums (Prunus domestica L. and other species and subspecies from the genus Prunus, Rosaceae) [8].

In the case of medicinal plants, there are many species described with ellagic acid in their chemical composition. Previously, García-Niño and Zazueta [50] reviewed the presence of ellagic acid in 32 medicinal plants. In the present review, we compiled some recent studies in which ellagic acid was isolated or identified $(\triangleright$ Table 1$)$. For this purpose, we selected a limited number of papers with a total of 43 species, and in some cases the botanical name is not same that the original paper because we use the last taxonomical review.

Various pharmacological properties of ellagic acid have been reviewed and described by Derosa et al. [6] and Larrosa et al. [8]. Knowledge of several of these properties comes from the use of medicinal plants in folk medicine; many have been studied in animals, while other properties have been evaluated in humans. This review will focus only on the most recent studies and discoveries of ellagic acid's relevant properties, such as its antioxidant activity, implicated in most of its pharmacological activities. These include its anti-inflammatory, neuroprotective, and hepatoprotective effects, as well as the protection it provides against diabetes, cardiovascular disease, and cancer [50,51]. However, ellagic acid's antioxidant effects are not the only factor involved, but act alongside other mechanisms of interest. For this reason, we will also review several relevant aspects of its pharmacokinetic properties and its efficacy in humans.

For this review, we selected the most relevant articles published from 2005 to the present. Papers published before 2005 were used only if they added special insights to be included in the introduction and discussion sections. Our search was conducted in PubMed, Scopus, the Web of Science, and the Cochrane Library. The keywords selected were "ellagic acid", either alone or combined with "antioxidant", "anti-inflammatory", "hepatoprotection", "liver", "neuroprotection”, "cardiovascular", 
- Table 1 Presence of ellagic acid on different medicinal plants. This review compiles only the more recent papers in which ellagic acid was isolated or identified.

\begin{tabular}{|c|c|c|}
\hline Plant species & Family & References \\
\hline Acalypha hispida Burm.f. & Euphorbiaceae & [9] \\
\hline Acca sellowiana (O.Berg) Burret* & Myrtaceae & [10] \\
\hline Baccharis inamoena Gardner* & Compositae & {$[11]$} \\
\hline Camellia nitidissima C. W.Chi* & Theaceae & [12] \\
\hline Campomanesia adamantium (Cambess.) O.Berg & Myrtaceae & [13] \\
\hline Canarium album (Lour.) DC.* & Burseraceae & {$[14]$} \\
\hline Carpobrotus edulis (L.) N. E.Br. & Aizoaceae & [15] \\
\hline Castanea crenata Sieb. \& Zucc. & Fagaceae & [16] \\
\hline Clematis ispahanica Boiss. & Ranunculaceae & [17] \\
\hline Clematis orientalis $\mathrm{L}$. & Ranunculaceae & [17] \\
\hline Clerodendrum infortunatum L.* & Lamiaceae & [18] \\
\hline Cornus officinalis Siebold \& Zucc. & Cornaceae & [19] \\
\hline Elaeagnus rhamnoides (L.) A.Nelson* & Elaeagnaceae & [20] \\
\hline Euterpe edulis Mart. & Arecaceae & [21] \\
\hline Eugenia uniflora $\mathrm{L}$. & Myrtaceae & {$[22]$} \\
\hline Euphorbia pekinensis Rupr. & Euphorbiaceae & [23] \\
\hline Geum urbanum L. & Rosaceae & [24] \\
\hline Gymnanthes lucida Sw.* & Euphorbiaceae & [25] \\
\hline Juglans regia $\mathrm{L}$. & Juglandaceae & [26] \\
\hline Lafoensia pacari A. St.-Hil. & Lythraceae & [27] \\
\hline Myrciaria floribunda (H.West ex Willd.) O.Berg & Myrtaceae & [28] \\
\hline Myrtus communis L. & Myrtaceae & [29] \\
\hline Nephelium lappaceum L. & Sapindaceae & [30] \\
\hline Pandiaka angustifolia (Vahl) Hepper & Amaranthaceae & [31] \\
\hline Phyllanthus acuminatus Vahl & Phyllanthaceae & [32] \\
\hline Pleurotus eryngii (DC. ex Fr.) Quel & Pleurotaceae & [33] \\
\hline Plinia cauliflora (Mart.) Kausel* & Myrtaceae & [34] \\
\hline Plinia coronata (Mattos) Mattos* & Myrtaceae & [35] \\
\hline Plinia peruviana (Poir.) Govaerts & Myrtaceae & [36] \\
\hline Potentilla anserina L. & Rosaceae & [37] \\
\hline Psidium brownianum Mart. ex DC & Myrtaceae & [38] \\
\hline Quassia undulata (Guill. \& Perr.) D.Dietr. & Simaroubaceae & [39] \\
\hline Salacia chinensis L. & Celastraceae & {$[40]$} \\
\hline Sambucus lanceolata R.Br. & Adoxaceae & {$[41]$} \\
\hline Sanguisorba officinalis L. & Rosaceae & {$[42]$} \\
\hline Sedum roseum (L.) Scop.* & Crassulaceae & {$[43]$} \\
\hline Sterculia striata A. St.-Hil. \& Naudin & Malvaceae & [44] \\
\hline Syzygium calophyllifolium (Wight) Walp. & Myrtaceae & {$[45]$} \\
\hline Syzygium cumini (L.) Skeels & Myrtaceae & {$[46]$} \\
\hline Terminalia chebula Retz. & Combretaceae & [47] \\
\hline Tetrapleura tetraptera (Schum. \& Thonn.) Taub. & Leguminosae & [39] \\
\hline Tocoyena formosa (Cham. \& Schltdl.) K.Schum. & Rubiaceae & {$[48]$} \\
\hline Zanthoxylum armatum DC.* & Rutaceae & [49] \\
\hline
\end{tabular}

*These plants are cited with the present name according to “The plant list. A working list of all plant species." Available at http://www.theplantlist.org/ 
"heart”, "blood pressure”, “hypertension”, “metabolic syndrome”, “cholesterol”, “hypercholesterolemia”, “lipid”, “hyperlipidemia”, “hypertriglyceridemia”, “diabetes”, “hyperglycemia”, “insulin”, “cytotoxic”, "antitumor”, "anti-infectious”, "antiviral”, "antibacterial”, “parasiticidal”, "clinical trials”, and "pharmacokinetic".

Relevant in vitro and in vivo studies were analyzed, as well as clinical trials. Only articles written in English and published in peer-reviewed scientific journals were selected. About 1480 papers on ellagic acid were published between 2005 and the present. Of these, we retrieved and analyzed approximately 250 and included 150 in the final review. As an initial reference we used the last review published in each subject, excluding articles if they included data from previous studies or with similar results. Finally, we focused the review on what we considered to be the most relevant topics: antioxidant and anti-inflammatory properties; metabolic syndrome, hepatoprotection, cardiovascular, anticancer, and skin disease effects; and pharmacokinetic and clinical trials.

\section{Ellagic Acid as an Antioxidant Agent}

Ellagic acid is one of the major antioxidants, along with the wellknown vitamins ascorbic acid and $\alpha$-tocopherol [52]. Its intrinsic antioxidant properties have been attributed to its free radical scavenging activity, which has been proposed to be similar to that of essential vitamins. As commented above, the presence of four hydroxyl and two lactone functional groups enables ellagic acid to scavenge a wide variety of ROS and reactive nitrogen species [53]. Indeed, studies show that at physiological pH, ellagic acid in aqueous solution can deactivate not only hydroxyl radical $\left(\mathrm{HO}{ }^{\circ}\right)$, but also peroxyl radicals $\left(\mathrm{ROO}{ }^{\circ}\right)$, nitrogen dioxide $\left(\mathrm{NO}_{2}{ }^{\circ}\right)$, and peroxynitrite $\left(\mathrm{ONOO}^{-}\right)[54,55]$. The scavenging efficacy of an antioxidant can be determined with the scavenging rate constant, which is the rate of the compound's reaction with free radicals in a given system. Tiwari and Mishra [56] demonstrated that ellagic acid is a good radical scavenger, particularly against $\mathrm{OH}^{\bullet}$, methoxyl $\left(\mathrm{OCH}_{3}{ }^{\circ}\right)$, and nitrogen dioxide $\left(\mathrm{NO}_{2}{ }^{\circ}\right)$, in descending order of scavenging rates $\left(\mathrm{OH}^{\cdot}>>\mathrm{OCH}_{3}{ }^{\bullet}>\mathrm{NO}_{2}{ }^{\circ}\right)$. These authors thus suggested that ellagic acid should, in general, be a more efficient scavenger of ROS than of reactive nitrogen species. This antiradical property is not reduced upon metabolism, as the metabolites of ellagic acid are also capable of efficiently scavenging a wide range of free radicals, often even faster than ellagic acid itself. Moreover, under specific environmental conditions, ellagic acid is predicted to be continuously regenerated after scavenging two free radicals, one peroxyl $\left(\mathrm{ROO}^{\circ}\right)$ and one superoxide $\left(\mathrm{O}_{2}{ }^{-}\right)$per cycle, until some of the intermediates are consumed in different reactions. This increases protective effects of ellagic acid at low concentrations, which is both a desirable and unusual behavior for an antioxidant [55].

The mechanism behind ellagic acid's scavenging activity is related to its ability to transfer the phenolic $\mathrm{H}$-atom to a free radical. The formal $\mathrm{H}$-atom abstraction from ellagic acid reaction has been shown to involve complex processes that proceed via at least three different mechanisms: hydrogen atom transfer, single electron transfer followed by proton transfer, and sequential proton loss electron transfer [57]. In aqueous solutions, the predicted mechanism is the loss of a proton from ellagic acid followed by electron transfer to free radicals, whereas in the gas phase or in nonpolar solvents, the reaction probably entails a hydrogen atom transfer to free radicals [58]. Specifically, the hydroperoxyl radical $\left(\mathrm{HOO}{ }^{\circ}\right)$ scavenging activity of ellagic acid has been found to take place exclusively through the hydrogen atom transfer mechanism, regardless of the polarity of the environment. In contrast, the relative importance of the various reaction paths is influenced significantly by the polarity of the environment. Compared to other antioxidants, the peroxyl radical scavenging activity of ellagic acid in lipid media was found to be lower than that of carotenes, dopamine, canolol, hydroxytyrosol, sesamol, sinapinic acid, protocatechuic acid, capsaicin and $\alpha$-mangostin; similar to that of tyrosol and melatonin; and higher than that of caffeine. Surprisingly, while ellagic acid is predicted to react about 7.9 times more slowly than Trolox, in aqueous solution it is predicted to react with hydroperoxyl radical 1.8 times faster than Trolox. With regard to other antioxidants, it is predicted to have higher peroxyl radical scavenging activity than melatonin, caffeine, allicin, and thioacrolein; similar activity to that of dopamine; and lower activity than that of canolol, $\alpha$-mangostin, protocatechuic acid, 2-propenesulfenic acid, glutathione, and sesamol [55].

In summary, ellagic acid exhibits antioxidant-sparing activity through the scavenging of free radicals, which may account for its protective effect against free radical-induced damage. In their study, lino et al. $[59,60]$ suggested that the protective effect of ellagic acid (3-30 mg/kg, p.o.) on gastric lesions induced by $\mathrm{NH}_{4} \mathrm{OH}$ in the ischemic stomach may arise through the scavenging of $\mathrm{NH}_{2} \mathrm{Cl}$, a causative factor in this lesion model, in addition to that of superoxide and hydroxyl anions $[59,60]$. Treatment with ellagic acid (50 mg/kg b. w., p. o.) also resulted in a significant decrease in the activity of serum liver enzymes as well as a decrease in total bilirubin and direct bilirubin serum levels, which may be responsible for inducing excessive free radical production leading to severe hepatic injury [50]. In addition, through its scavenging action on free radicals, ellagic acid indirectly reduced serum level of triglycerides, total cholesterol, and the fraction of LDL and VLDL. These results are in agreement with previous reports showing the hypolipidemic activity ellagic acid [53].

Particularly, hydroxyl and peroxyl radicals are involved in the initiation and propagation of lipid peroxidation, respectively. Ellagic acid has been reported to be effective in inhibiting lipid peroxidation, even at $\mu \mathrm{M}$ concentrations [54]. Its protective effect has been attributed mainly to its role as a free radical scavenger; indeed, it has been proposed to be a better free radical scavenger than vitamin E succinate [61] and equal to a two- to threefold Trolox [62]. This is in agreement with Böyük et al. [63], who reported for the first time that ellagic acid $(85 \mathrm{mg} / \mathrm{kg}$, p.o) was effective in protecting lung tissue against ischemia reperfusion oxidative stress through a reduction in the increase of lipid peroxidation as well as a reduction in oxidative stress parameters. Uzar et al. [64] found that ellagic acid $(50 \mathrm{mg} / \mathrm{kg} / \mathrm{d})$ caused a decrease in streptozotocin-elicited lipid peroxidation and counteracted streptozotocin-induced impairment of total oxidant status and the oxidative stress index. More recently, Kilic et al. [65] demonstrated that the protective effect of ellagic acid (59\%) on the lipid peroxidation of linoleic acid emulsion was similar to that of ascorbic acid (60\%) 
but lower than that of p-coumaric acid (72\%), while Roche et al. [66] asserted that the reduction in lipid peroxidation provides clear evidence of the antioxidant effects of ellagic acid.

It has been established that ROS are generated during the reaction of CYP with its substrate; however, the microsomal electron-transfer chain continues to oxidize NADPH-oxidase and produce ROS even in the absence of any substrate. In addition, enzymes such as lipoxygenase, COX, and xanthine oxidase can also contribute to ROS production. Hassoun et al. [67] suggested that ellagic acid ( $1 \mathrm{mg} / \mathrm{kg} / \mathrm{d}, 13 \mathrm{wk}$ ) prevented the upregulation of CYP expression through an indirect antioxidant effect. However, in their study, they did not elaborate on how ellagic acid decreases superoxide production through the mitochondrial function, an important detail, as this organelle is the main site of superoxide production in mammalian cells. In other research, ellagic acid (5$20 \mu \mathrm{M}$, in vitro) was shown to exert its beneficial effect on oxidized LDL-induced endothelial dysfunction by suppressing the membrane assembly of the NADPH oxidase complex, thereby decreasing the overproduction of superoxide radicals [68]. In this context, Berkban et al. [69] suggested that ellagic acid reduces oxidative stress by decreasing NADPH oxidase subunit p47phox expression. However, to date, no study has produced conclusive evidence for this hypothesis.

The presence of ionic metals such as copper or iron in a system can accelerate the rate of oxidation in that system. Phenolic compounds such as ellagic acid have been shown to inhibit the pro-oxidative action of metals by means of a chelation process in which the phenolics bind with the metal ions to form a complex incapable of promoting oxidation [70]. Through this chelation process, they operate as "secondary" or "preventive" antioxidants, thus inhibiting oxidation without directly interacting with oxidative species [71]. In a previous study, Ahmed et al. [72] had demonstrated that ellagic acid $(500 \mu \mathrm{mol} / \mathrm{kg}$ b.w.) was a potent chelating compound for suppressing nickel-induced oxidative stress in the liver and kidney of female Wistar rats. In another study, ellagic acid (30 $\mathrm{MM}$ for $24 \mathrm{~h}$ ) effectively counteracted cadmium-induced ROS generation, thus blocking the cadmium-mediated apoptosis of astrocytes, the most abundant glial cells in the central nervous system [73]. Even though the authors did not describe the molecular mechanism by which ellagic acid exerts such protective effects upon primary astrocytes, its ability to chelate metal ions may be involved. Moreover, ellagic acid was shown to have an effective chelating effect on ferrous ion $(45 \mu \mathrm{g} / \mathrm{mL}, 49 \%)$, which was similar to that of other phenolic compounds such as caffeic acid $(15 \mu \mathrm{g} /$ $\mathrm{mL}, 53 \%$ ) [65]. More recently, Saha et al. [74] demonstrated that ellagic acid $(10 \mu \mathrm{M})$ is capable of binding iron in a similar way to epigallocatechin gallate. The presence of a catechol group in the former was identified as being responsible for iron chelation ( $\bullet$ Fig. 2) [75]. Finally, Galano et al. [55] concluded that after deprotonation, ellagic acid is also capable of chelating copper in aqueous solution, yielding stable complexes. All these reactions predictably decrease free radical production; thus, metal chelation is another way in which ellagic acid exerts its protective effect against oxidative stress.

Another potential protective mechanism of ellagic acid against oxidative stress involves shielding DNA from attack through a direct association with this macromolecule. The formation of 8-oxo-

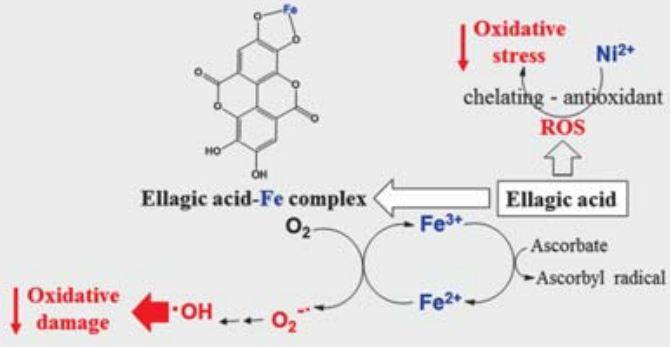

- Fig. 2 Effect of ellagic acid on different metals. Proposal mechanism of chelation (adapted from Dalvi et al. [75]).

2 '-deoxyguanosine is a benchmark of oxidative DNA damage. Various studies have shown that ellagic acid significantly decreases the amount of 8-oxo-2'-deoxyguanosine produced after oxidative DNA damage $[63,76]$, which was consistent with an earlier report [77]. This protective behavior also correlates with a previous study on the interaction between ellagic acid and DNA, where ellagic acid was shown to bind directly to DNA, likely leading to the protection of binding sites from free radicals $[78,79]$. In their study, Spencer et al. [80] showed that ellagic acid substantially inhibited dopamine/ $\mathrm{Cu}^{2+}$-mediated oxidative DNA decomposition at all doses tested $(1,6,30$, and $150 \mu \mathrm{M})$; in fact, even at doses as low as $1 \mu \mathrm{M}$, the inhibition was nearly $50 \%$. These results, coupled with those of a recent study indicating that dietary ellagic acid $(1 \mathrm{mg} / \mathrm{kg} / \mathrm{d}, 13 \mathrm{wk})$ significantly protected rat brain tissue from tetrachlorodibenzo-p-dioxin-induced superoxide anion production, lipid peroxidation, and DNA strand breaks [67], support the potential role of ellagic acid in neuroprotection from oxidatively generated DNA damage.

Regulation of endogenous antioxidant enzymes by exogenous antioxidants should be an effective way to prove ellagic acid's antioxidant capacity. Nrf2 is a redox-sensitive transcription factor that acts as the master antioxidant response regulator in the cell. Under stressful and toxic conditions, Nrf2 translocates into the nucleus where, after binding to DNA, it induces transcription of genes related to the antioxidant defense system [81]. In this regard, ellagic acid $(5,12$, and $30 \mu \mathrm{M})$ has been shown to play a defensive role against UV-B light-induced oxidative stress through upregulation of the Nrf2 signaling pathway in human dermal fibroblasts [82] and may even augment the nuclear translocation and transcriptional activation of Nrf2 [83] in human keratinocyte cells. A study by $\mathrm{Gu}$ et al. [84] reported that ellagic acid (5, 10, $20 \mathrm{mg} / \mathrm{kg}$ b.w., i.p.) may protect against acute hepatic injury in mice by inducing the expression of $\mathrm{Nrf2}$ and $\mathrm{HO}-1$. In addition, consistent ellagic acid consumption within a nutritional range $(0.5 \mathrm{~g} / \mathrm{kg}$ diet, for a dose of about $30 \mathrm{mg} / \mathrm{kg} / \mathrm{d}, 14 \mathrm{wk})$ has been shown to attenuate endothelial dysfunction and atherosclerosis in mice fed with a high-fat (21\%) diet, a finding that has been partly attributed to ellagic acid's induction of the oxidative defense system through its effects on Nrf2. However, although these results confirm that the intake of ellagic acid can have a pharmacological effect, the authors did not evaluate the molecular mechanism through which ellagic acid modulates the nuclear 
translocation of Nrf2 [85]. Other studies have since revealed that the activation of Nrf2 in human keratinocyte cells by ellagic acid involves an ROS-independent pathway, suggesting that the presence of the $\alpha, \beta$-unsaturated ketone moiety chemical backbone in ellagic acid is responsible for its potent activation of Nrf2 [83].

In cases of oxidative stress or lipid peroxidation, the cellular defense system operates mainly via antioxidant enzymes such as catalase, superoxide dismutase, glutathione peroxidase, glutathione S-transferase, and glutathione reductase. Earlier reports $[83,86]$ showed that ellagic acid increased the levels of the antioxidant glutathione $S$-transferase (as well as the enzyme involved in the synthesis of glutathione, glutamate-cysteine ligase) severalfold in rat livers. Induction of glutathione S-transferase and the enhancement of glutathione levels can both protect against the oxidative damage generated by many carcinogens as well as influence redox-sensitive signaling pathways involved in response to stress [87]. More recently, Mishra and Vinayak [88] demonstrated that ellagic acid (60 and $80 \mathrm{mg} / \mathrm{kg}$ b.w., p.o.) improves the antioxidant defense system by increasing the expression and activity of the antioxidant enzymes catalase, superoxide dismutase, glutathione peroxidase-4, and glutathione reductase, both in liver and ascites cells of Dalton's lymphoma-bearing mice. Thus, because of its indirect activity inhibiting ROS formation, ellagic acid has been proposed as potential new drug in the treatment of cirrhosis induced by chemical agents, such as $\mathrm{CCl}_{4}$ [89].

\section{Anti-Inflammatory Activity of Ellagic Acid}

Inflammation and oxidative stress are closely related pathophysiological events that are tightly linked with one another [90]. Apart from its well-known antioxidative effects, ellagic acid has also been shown to exert potent anti-inflammatory activities [88]. For this reason, several studies have emphasized the potential of ellagic acid as a candidate for the treatment of many chronic inflammatory diseases and conditions [91-93]. In this review, we will cite the most relevant studies, specifically those focused on the mechanism of action. For example, ellagic acid has been shown to inhibit key cell functions and activation of pancreatic stellate cells, which play a pivotal role in the pathogenesis of pancreatic fibrosis and inflammation. In their study, Masamune et al. [94] demonstrated that ellagic acid $(1,5,10,25 \mu \mathrm{g} / \mathrm{mL})$ inhibits IL- $1 \beta$ and TNF- $\alpha$-induced activation of AP- 1 and MAPK, such as ERK $1 / 2$, JNK, and p38, but not NF-KB. These results are concordant with those from a study carried out by González-Sarrías et al. [95], who reported that ellagic acid $(10 \mu \mathrm{M})$ did not attenuate NF- $к B$ activation, as seen by the lack of anti-inflammatory activity in colon fibroblasts after IL- $1 \beta$ treatment. However, the inhibition of MAPK activation was likewise not observed in this study. These contradictory results regarding MAPK activation were attributed to the different MAPK activation patterns, depending on the cell type. In their work, Cornélio Favarin et al. [96] showed that ellagic acid $(10 \mathrm{mg} / \mathrm{kg}$ b. w., p.o.) reduced the pro-inflammatory cytokine IL-6 and increased the anti-inflammatory cytokine IL-10 in the bronchoalveolar lavage fluid in acid-initiated acute lung injury without downregulating the NF-KB and AP-1 signaling pathways. This was in contrast with the effects of dexamethasone $(1 \mathrm{mg} / \mathrm{kg}$ b. w., s.c.), suggesting that the effect of ellagic acid on acute lung injury-associated inflammation is not NF- $\kappa$ B and AP-1 dependent. In contrast, NF- $\kappa \mathrm{B}$ was a potential target for the anti-inflammatory effect of ellagic acid incorporated into the normal diet $(0.5 \%)$ of mice in an ulcerative colitis experimental model [97]. Similar results for ellagic acid as an anti-inflammatory agent through modulation of the NF- $K B$ activation pathway have been observed in several other studies [98-102].

The transcription factor NF- $\kappa \mathrm{B}$ has been shown to be a critical regulator of COX-2 expression [103]. For this reason, El-Shitany et al. [104] studied ellagic acid (100 mg/kg b.w., i. p.), demonstrating its ability to modulate the production of COX-2 mRNA mainly through the inhibition of ROS production, which in turn inhibits NF- $K$ B activation. In their study, COX-2 mRNA expression was also blocked by meloxicam ( $4 \mathrm{mg} / \mathrm{kg}$ b.w., i. p.) but was not affected by indomethacin $(10 \mathrm{mg} / \mathrm{kg}$ b.w., i. p.). Moreover, it was shown that ellagic acid has an even higher binding affinity than that of diclofenac or meloxicam. The binding pattern of ellagic acid with the COX-2 active site shows that it makes four hydrogen bonds with Arg120, Ser530, Tyr355, and Tyr385, while meloxicam makes three hydrogen bonds and diclofenac makes only two hydrogen bonds. Thus, researchers have suggested that ellagic acid may inhibit carrageenan-induced acute inflammation by blocking the COX-2 receptor, as is the case with both diclofenac and meloxicam [104]. In parallel, prostaglandin $\mathrm{E}_{2}$ (a metabolite of COX-2) is considered to be one of the strongest mediators in the inflammatory response. Ellagic acid was able to inhibit this compound in human monocytes in a dosage range of $10-30 \mu \mathrm{M}$. This effect was mediated by the inhibition of the lipopolysaccharide-induced expression of the cytosolic phospholipase $A_{2} \alpha, C O X-2$, and mPGEs- 1 proteins, not through a direct effect on enzyme activity. The mechanism by which ellagic acid inhibited the lipopolysaccharide-induced expression of all three enzymes was thought to involve effects on protein kinases and/or transcription factors. As mentioned above, ellagic acid has been shown to inhibit various protein kinases [105]. Among these, MAPK $[94,97,99,106]$ are of special interest since they seem to participate in the regulation of the expression of both COX-2 [107-109] and mPGEs-1 [110]. Both in vitro and in vivo studies have indicated an existing crosstalk between the release of prostaglandins and NO in the modulation of inflammation. It is thus significant that ellagic acid (10 and $30 \mathrm{mg} / \mathrm{kg}$ b.w., i. p.) has been shown to inhibit NO production significantly by downregulating inducible NO synthase [111,112].

The binding and recruitment of circulating monocytes to vascular endothelial cells are early steps in the development of inflammation and atherosclerosis. These processes are mediated through cell adhesion molecules that are expressed on the surface of endothelial cells. In their study, Papoutsi et al. [113] tested ellagic acid at a concentration range of $0.1-10 \mu \mathrm{M}$ and found that it inhibited the TNF- $\alpha$-induced endothelial activation and expression of both VCAM-1 and ICAM-1. In contrast, Yu et al. [114] demonstrated that ellagic acid at a concentration of $25-50 \mu \mathrm{M}$ reduced IL-1 $\beta$-induced expression of VCAM- 1 and E-selectin, but not of ICAM-1. Their finding that ellagic acid exerted its anti-inflammatory effects via modulation of NF- $\kappa$ B activity is noteworthy. In other work, ellagic acid (10 mg/kg b.w., p. o.) has been consistently shown to decrease the expression of P-selectin in the bronchial epithelium of ovalbumin-immunized and challenged mice [115]. 
Various secreted pro-inflammatory cytokines, such as macrophage MIF, play key roles in mediating inflammatory responses. Particularly, it has been shown that MIF induces nuclear translocation of NF- $\kappa$ B and chemotaxis of peripheral blood mononuclear cells to promote inflammation. Sarkar et al. [116] have shown that ellagic acid $(50 \mu \mathrm{M})$ inhibits the tautomerase activity of MIF and MIF-mediated pro-inflammatory responses in peripheral blood mononuclear cells $\left(\mathrm{IC}_{50} 4.77 \pm 0.52 \mu \mathrm{M}\right)$. Although the exact mechanism was not elucidated, the authors suggest that ellagic acid's ability to block tautomerase activity or the tautomerase-active site of the cytokine could contribute to the inhibition. The cytokines TNF- $\alpha$ and IL-6 are related to humoral and cellular inflammation, respectively. In lipopolysaccharide-stimulated RAW 264.7 cells, ellagic acid significantly inhibited TNF- $\alpha$ and IL-6 production, even at $\mu \mathrm{M}$ concentrations [117]. It also decreased production of IL-13 (at $100 \mu \mathrm{M}$ ) from stimulated human peripheral blood mononuclear cells, whereas no change was observed in IL-4 and TNF- $\alpha$ production [118]. Moreover, dietary administration of ellagic acid ( $5 \mathrm{~g} / 100 \mathrm{~g}$ standard power diet) has been shown to lower cardiac and renal levels of IL- $1 \beta$, IL- 6 , TNF- $\alpha$, and MCP- 1 while also significantly downregulating TNF- $\alpha$ and MCP- 1 mRNA expression in the kidney. In addition, intake of ellagic acid substantially decreased renal IL-1 $\beta$, IL-6, and TNF- $\alpha$ levels in diabetic mice [91]. Topical application of ellagic acid $(1-10 \mu \mathrm{M})$ diminished production of pro-inflammatory cytokines IL- $1 \beta$ and IL- 6 as well as adhesion molecule ICAM- 1 in the dermis, and also mitigated infiltration of inflammatory macrophages in UV-B-inflamed hairless mouse skin [119]. Oral treatment of gastric ulcerated mice with ellagic acid at a dose of $7 \mathrm{mg} / \mathrm{kg}$ significantly reduced the levels of pro-inflammatory cytokines TNF- $\alpha, \mathrm{IL}-1 \beta$, and IL- 6 while inducing anti-inflammatory cytokines IL-4 and IL-10 [120]. In agreement with these studies conducted with various experimental models, ellagic acid treatment of mice with adjuvant-induced arthritis significantly decreased levels of IL-1 $\beta$ and TNF- $\alpha$ [121]. Although the precise mechanism by which ellagic acid decreases serum levels of these pro-inflammatory cytokines is unclear, it has been suggested that the compound acts through direct inhibition of the NF- $\kappa$ B pathway [122].

IL-17 is a pro-inflammatory cytokine known to stimulate the production of other inflammatory cytokines and chemokines $[123,124]$. To date, two studies have demonstrated ellagic acid's ability to decrease serum levels of IL-17 in different experimental mouse models. First, Allam et al. [121] showed that ellagic acid treatment $(58.33 \mathrm{mg} / \mathrm{kg}$ b.w., i. p.) was effective in reducing serum levels of IL-17 in arthritic mice, while more recently, Sanadgol et al. [125] found that ellagic acid (40 and $80 \mathrm{mg} / \mathrm{kg} / \mathrm{d}$ i. p., 4 wk) decreases IL-17 expression at both the protein and mRNA level. These results are in harmony with a previous study demonstrating that pomegranate juice rich in ellagic acid $(25 \mu \mathrm{g} / \mathrm{mL})$ inhibited the synthesis of IL-17 from human peripheral blood mononuclear cells [126]. Taken together, these studies show that ellagic acid is capable of downmodulating pro-inflammatory mediators and stimulating the production of anti-inflammatory cytokines.

Activation of TLR2 and TLR4 facilitates the activation of the MAPK and IKK complex pathways, which transduce various upstream signals leading to activation of AP- 1 and NF- $\kappa$ B transcription factors. In a study conducted by Lee et al. [127], pre-treatment with ellagic acid $(50,100$, or $200 \mathrm{mg} / \mathrm{kg}$ b.w., p. o.) reduced TLR2 and TLR4 protein levels as well as mRNA expression in liver tissue. These new results are extremely relevant because the effect of ellagic acid on these receptors had not previously been reported. The authors proposed that ellagic acid may have general anti-inflammatory effects in diseases associated with TLR signaling.

\section{Ellagic Acid in Metabolic Syndrome}

The term metabolic syndrome refers to a group of factors that raises the risk for heart disease and other health problems, including diabetes and stroke. This set of risk factors includes abdominal obesity, high triglyceride levels, low HDL-cholesterol levels, high blood pressure, and high fasting blood glucose levels [128]. Any one of these factors alone is a problem, such as high blood pressure or high fasting blood glucose, but when a patient presents with three of them, for example the two aforementioned factors plus abdominal obesity, a diagnosis of metabolic syndrome is likely [129]. Various studies have reported on the antihyperglycemic and antihyperlipidemic properties of ellagic acid, which were analyzed in vitro and in vivo [52,130-132]. Indeed, the effect of this acid on glucose metabolism has been widely investigated and represents the principal target for the compound's potential effects against metabolic syndrome (with several studies focusing on glucose and lipid metabolism in diabetic rats), as well as its effects on obesity.

Working in vitro, Pinto Mda et al. [133] demonstrated that ellagic acid has good potential for the management of hyperglycemia and hypertension linked to type 2 diabetes. They studied the effects of ellagic acid, purified ellagitannins, and a strawberry extract (a good source of ellagic acid) as inhibitors of $\alpha$-amylase, $\alpha$ glucosidase, and angiotensin I-converting enzyme, and they observed that purified ellagitannins and ellagic acid inhibited $\alpha$-amylase and angiotensin-converting enzymes but had a limited inhibitory effect on $\alpha$-glucosidase.

Malini et al. [134] studied the antidiabetic effects of ellagic acid (50 and $100 \mathrm{mg} / \mathrm{kg}$, for $35 \mathrm{~d}$ ) in streptozotocin-induced diabetes in rats. The acid reduced the concentration of glucose in plasma, along with insulin, $\mathrm{HbA} 1 \mathrm{c}$, and hexokinase activity, while simultaneously decreasing glycogen (liver and muscle), as well as glucose-6-phosphatase and fructose-1,6-bisphosphatase activity in the liver and kidney, all with respect to the increased values in diabetic rats. In other assays, Uzor and Osadebe [135] studied the antidiabetic activity of ellagic acid $(20 \mathrm{mg} / \mathrm{kg})$ in alloxan-induced diabetes in mice. The compound was isolated from the roots of Combretum comosum var. dolichopetalum (Engl. \& Diels) Jongkind (Combretaceae, syn: Combretum dolichopetalum Engl. \& Diels), a plant used as an antidiabetic remedy in Nigerian folk medicine. Ellagic acid $(10 \mathrm{mg} / \mathrm{kg}$, p.o., $2 \mathrm{wk}$ ) reduced fasting blood glucose by $24 \%$ at $9 \mathrm{~h}$ [135]. It also improved the glucose/ insulin balance, lipid profile, redox level, and the levels of liver enzymes, inflammatory cytokines, and adipokines in serum and tissues (liver, pancreas, adipose tissue, and brain) while enhancing insulin signaling, adiponectin receptors, glucose transporters, and inflammatory mediators. These experiments were performed in rats fed with a high-fat fructose diet for 2 mo to induce insulin resistance and type 2 diabetes [136]. 
In a previous report, Ueda et al. [137] described the effects of ellagic acid on sorbitol accumulation in vitro and in vivo, reporting inhibitory activity for this compound on sorbitol accumulation in erythrocytes, the lens, and the sciatic nerve under incubation with glucose in vitro. The $\mathrm{IC}_{50}$ of ellagic acid against sorbitol accumulation in erythrocytes was $2.4 \mu \mathrm{M}$, whereas in the case of the lens and sciatic nerve, the effect was quite limited (at $400 \mu \mathrm{M}$, the inhibition was $14 \%$ and $32 \%$, respectively). When the effect was analyzed on diabetic rats, ellagic acid at 50,75 , and $100 \mathrm{mg} / \mathrm{kg} / \mathrm{d}$ reduced the elevated sorbitol accumulation in erythrocytes, the lens, and the sciatic nerve, with the middle dose $(75 \mathrm{mg} / \mathrm{kg} / \mathrm{d}$ ) producing the best effect. Chao et al. [91] studied the protective effects of ellagic acid ( 2.5 and $5 \%$ in the diet for $12 \mathrm{wk}$ ) on the kidneys of diabetic rats. The intake of ellagic acid increased plasma insulin and decreased blood glucose levels at weeks 6 and 12; at the higher dose, it also decreased plasma levels of HbA1c. In addition, it reduced sorbitol and fructose levels in plasma and suppressed the aldose reductase mRNA expression in the kidney. Ellagic acid also lowered renal levels of IL- 6 , IL-1 $\beta$, TNF- $\alpha$, and MCP-1, downregulating the mRNA expression of the latter proteins in the kidney. Taken together, these results provide clear evidence that ellagic acid possesses antiglycation properties as well as anti-inflammatory effects; for this reason, it may aid in the prevention or attenuation of diabetic kidney disease.

Panchal et al. [138] analyzed the effects of ellagic acid $(0.8 \mathrm{~g} /$ $\mathrm{kg}$ in food, 8-16 wk) on high-carbohydrate, high-fat diet-induced metabolic syndrome in rats. This experimental model produces impaired glucose tolerance, with increased protein levels of NF$\kappa \mathrm{B}$ and decreased protein levels of Nrf2 and carnitine palmitoyl transferase 1 in the heart and liver. After administration, ellagic acid attenuated the symptoms of metabolic syndrome provoked in this experiment, normalizing the protein levels of Nrf2, NF- $\kappa \mathrm{B}$, and carnitine palmitoyl transferase 1 . As described above, $\mathrm{Nrf2}$ is a regulator of cellular resistance to oxidants and plays a relevant role in oxidant stress resistance; its regulation is thus highly important in redox homeostasis [139]. The role of Nrf2 activation in the prevention of obesity, metabolic syndrome, nephropathy, retinopathy, and neuropathy has only recently been described, with the results indicating that its activation can prevent the development of complications in type 2 diabetes mellitus [140]. For example, NF- $\kappa$ B is activated by a wide variety of cell-stress stimuli (including hyperglycemia) as well as in cases of renal fibrosis. Its inhibition produces a significant amelioration of diabetic nephropathy, thus making it an excellent therapeutic target for avoiding this serious associated effect [141]. The ability of ellagic acid to inhibit the renal NF- $\kappa B$ pathway can thus improve the multifactorial response due to its antihyperglycemic, antiglycative, antioxidant, and anti-inflammatory properties [122].

Pomegranate extract and its principal components, including ellagic acid, were found to suppress the formation of AGE from bovine serum albumin and sugars [142]. Because hyperglycemia enhances the aldose reductase-related polyol pathway and increases AGE formation, these two processes may constitute good targets for counteracting their relevant roles in the complications of type 2 diabetes mellitus, such as cataracts [143]. Aldose reductase catalyzes the reduction of glucose to sorbitol, which is transformed into fructose by sorbitol dehydrogenase; consequently, in- creased fructose levels are a key factor in AGE formation. In diabetic patients, polyol levels rise and accumulate due to their poor penetration and metabolism, thus generating many of the complications of diabetes $[144,145]$. Taking this into account, Rao et al. [143] studied different plants and principles for their inhibitory activity against aldose reductase of different origin, as well as on the generation of AGEs. Among them, ellagic acid gave $I C_{50}$ values of $16 \mu \mathrm{M}$ (rat lens), $19 \mu \mathrm{M}$ (rat kidney), $9 \mu \mathrm{M}$ (human recombinant), and $18 \mu \mathrm{M}$ (AGE formation). In addition, in vivo inhibition of lens galactitol accumulation by ellagic acid in galactose-fed rats was also studied, giving an $\mathrm{IC}_{50}$ value of $6.3 \mu \mathrm{M}$. Aslan and Beydemir [146] studied the ability of ellagic acid to inhibit the enzymatic activity of aldose reductase and sorbitol dehydrogenase from sheep livers, establishing $I_{50}$ values of 7.0 and $13.0 \mu \mathrm{M}$, respectively, for each enzyme.

The formation of AGEs is accelerated in the case of hyperglycemia, which alters the structure and function of proteins, contributing to long-term diabetic complications. In this context, Muthenna et al. [147] studied the effects of ellagic acid as an antiglycating agent on different proteins, including hemoglobin and various glycating agents such as fructose, among others. The mechanism proposed by these authors for ellagic acid involves the inhibition of $\mathrm{N}^{\mathrm{E}}$-(carboxyethyl)lysine through scavenging of dicarbonyl compounds; they also demonstrated its effectiveness against loss of eye lens transparency through the inhibition of AGEs in the lens organ culture system. These results established the antiglycating effects of ellagic acid and its potential for controlling AGE-mediated diabetic pathologies, such as damage to the lens crystalline fibers, hemoglobin, and LDL, all of which are involved in type 2 diabetes mellitus and its associated complications [147]. The accumulation of AGEs has also been implicated in the pathogenesis of the vascular complications of diabetes, including diabetic nephropathy. In this case, ellagic acid was shown to prevent the accumulation of AGEs in streptozotocin-induced diabetes in rats. Indeed, addition of ellagic acid to food $(0.2 \%$ or $2 \%$, in the diet, $12 \mathrm{wk}$ ) prevented glycation-mediated red blood cell-immunoglobulin $\mathrm{G}$ cross-links and HbA1c accumulation while also inhibiting the accumulation of $\mathrm{N}$-carboxymethyl lysine, a predominant AGE in the diabetic kidney. It also ameliorated AGE-mediated pathogenesis of diabetic nephropathy [148].

A mechanism of great interest to researchers is the effect of ellagic acid on resistin, an adipocytokine considered to be the link between obesity and type 2 diabetes mellitus. In their work, Makino-Wakagi et al. [149] demonstrated that both ellagic acid and its source (pomegranate fruit juice) suppress resistin secretion by a novel mechanism involving the degradation of intracellular resistin protein in adipocytes but had no effect on adiponectin secretion. For the in vivo experiments, they only used pomegranate fruit juice and ovariectomized mice, an animal model with elevated resistin levels in serum and upregulated resistin mRNA expression in white adipose tissue. In this case, the treatment group presented a clear reduction in serum resistin levels versus the control group. These results, together with the in vitro data, gave rise to the hypothesis that ellagic acid is the active compound of the extract. In a second study, these same authors demonstrated that ellagic acid reduced serum resistin levels without altering mRNA 
expression in adipose tissue. They thus concluded that ellagic acid is a potent suppressor of resistin secretion in vivo [150].

Kam et al. [151] screened various pomegranate extracts and their major constituents and observed a poor inhibitory activity for ellagic acid against rat intestinal $\alpha$-glucosidase $(42 \%$ at $67 \mu \mathrm{g} /$ $\mathrm{mL}, \sim 222 \mu \mathrm{M})$, with no effect on porcine pancreatic $\alpha$-amylase. This effect was corroborated by Bellesia et al. [152], who observed a slight inhibitory activity for ellagic acid against $\alpha$-glucosidase, but in this case with an $\mathrm{IC}_{50}$ of $381 \mu \mathrm{M}$. These results indicate that the effects of ellagic acid on these enzymes are not significant; however, its effects on glycogen degradation and $\beta$-cell physiology and functionality seem to be more important in the acid's pharmacological effects on diabetes, most likely because glycogen phosphorylase catalyzes the first step in the intracellular degradation of glycogen to yield $\alpha$-D-glucose-1-phosphate. For this reason, this process may serve as a target for the discovery of specific inhibitors, which may then be used as antihyperglycemic agents [153]. In the case of ellagic acid, it is a significant inhibitor of this enzyme, with a $\mathrm{K}_{i}$ of $13.4 \mu \mathrm{M}$ and $7.5 \mu \mathrm{M}$ for glycogen phosphorylase-a and -b, respectively. It is a competitive inhibitor against the substrate, glucose-1-phoshate and noncompetitive with respect to the allosteric activator, AMP [154].

A direct mechanism on $\beta$-cells was proposed by Fatima et al. [155], who studied neonatal streptozotocin-induced nonobese type 2 diabetes in rats. Ellagic acid from Phyllanthus emblica L. (syn: Emblica officinalis Gaertn., Phyllanthaceae) was tested for its effects on glucose-stimulated insulin secretion and the glucose tolerance test. Indeed, this phenolic compound decreased glucose intolerance in nonobese type 2 rats ( $23 \%$ at $100 \mathrm{mg} / \mathrm{kg}$, after $45 \mathrm{~min}$ ) and stimulated glucose-induced insulin secretion in isolated islets at $100 \mu \mathrm{M}$ (5.8 ng insulin/islet/h vs. $2.1 \mathrm{ng}$ insulin/islet/h for glucose alone). The authors concluded that ellagic acid exerts antidiabetic activity through its effects on pancreatic $\beta$ cells, increasing both their size and number, as well as on serum insulin and antioxidant status, all while decreasing blood glucose.

In addition to its effects on glucose homeostasis, other factors involved in metabolic disease have also been analyzed. For example, when ellagic acid was tested against nonalcoholic fatty liver disease and atherosclerosis, the results showed that it can regulate lipid metabolism and reduce certain obesity-mediated metabolic complications [156]. The co-administration of ellagic acid and coenzyme $\mathrm{Q}_{10}$ to hyperlipidemic rats that were fed a highfat diet for 4 wk improved their endothelial function and hyperlipidemic conditions, lowering cholesterol, glucose, and triglyceride levels. In other experiments on diabetic rats, the effect of ellagic acid on LDL-cholesterol was also described. Because the oxidation of LDL is implicated in the origin and development of atherosclerotic plaque formation through endothelial inflammation, its reduction or attenuation is of interest for preventing metabolic syndrome and cardiovascular disease. Not only can LDL be oxidized in the subendothelial space, but monocytes will attach to endothelial cells that express cell adhesion molecules and inflammatory cytokines. The uptake of oxidized-LDL via scavenger receptors leads to foam cell formation; the oxidized-LDL cholesterol taken up this way will then be subject to esterification and storage in lipid droplets, converted to more soluble forms, or exported to extracellular HDL acceptors [157]. In their study, Park et al. [158] demonstrated that ellagic acid reduced oxidized LDL uptake and cholesterol influx while suppressing both SRB1 induction and foam cell formation in murine oxidized-LDL-stimulated macrophages. At $\leq 5 \mu \mathrm{M}$, ellagic acid also upregulated PPARy and $A B C A 1$, all responsible for cholesterol efflux, in lipid-laden macrophages. It also accelerated the expression and transcription of the nuclear receptor of LXR- $\alpha$. Several studies have demonstrated the central role of PPAR-y in governing cholesterol homeostasis through the influence of LXR in macrophages, enhancement of the expression of $A B C A 1$, and reduction of the membrane expression of SRB1 [159]. Because ellagic acid works as a PPARy modulator, administration of this phenolic compound can transfer effluxed cholesterol onto lipid-poor apolipoproteins, initiating the formation of HDL particles. In this way, it acts as an anti-atherogenic agent, blocking foam cell formation and/or enhancing cholesterol efflux pertaining to reverse cholesterol transport [158]. In addition, Rani et al. [160] demonstrated the efficacy of ellagic acid in preventing platelet-derived growth factor-BB-induced proliferation of primary cultures of rat aortic smooth muscle cells, along with its ability to prevent atherosclerosis in streptozotocininduced diabetes in rats. Indeed, ellagic acid $(25 \mu \mathrm{M})$ blocked PDGFR- $\beta$, tyrosine phosphorylation, generation of intracellular ROS, and downstream activation of ERK $1 / 2$. In diabetic rats, ellagic acid ( $2 \%$ in the diet) blocked diabetes-induced lipid deposition in the arch of the aorta, reducing the atherosclerotic process by blocking the proliferation of vascular smooth muscle cells [160].

The principal antihyperglycemic effects of ellagic acid on glucose homeostasis that can modify the metabolic syndrome are summarized in $>$ Fig. 3 . The effect of ellagic acid on lipid and cholesterol metabolism and the positive consequences this has on atherogenic formation are summarized in > Fig. 4.

\section{Ellagic Acid as a Potential Neuroprotective Agent}

Various assays have been performed to determine the possible effect of ellagic acid as a neuroprotective agent. Many of these have focused on its antioxidant properties; however, other interesting features are also of interest. For example, in a recent review, de Oliveira [51] compiled both in vivo and in vitro studies on the neuroprotective activity of ellagic acid against different stressors, such as 2,3,7,8-tetrachlorodibenzo-p-dioxin, streptozotocin, the traumatic brain injury test, a transgenic model of Alzheimer's disease, and hypoxic ischemic brain lesion. It also cited the positive effects of ellagic acid on pro-oxidant and anti-inflammatory mediators and described the acid's ability to decrease lipid peroxidation, superoxide radical, NO, IL- $1 \beta$, IL-6, and TNF- $\alpha$ production, as well as to activate the nuclear factor of activated T-cells 1 and phosphorylated-IKB. In addition, ellagic acid increased catalase and paraoxanase- 1 activities and neuronal and memory function and decreased the amount of brain area lost. Mansouri et al. [161] assayed ellagic acid (30 and $100 \mathrm{mg} / \mathrm{kg}$ ) in two tests of memory impairment induced by scopolamine $(0.4 \mathrm{mg} / \mathrm{kg}$, i. p.) or diazepam $(1 \mathrm{mg} / \mathrm{kg}$, i.p.), demonstrating the efficacy of the compound in preventing both scopolamine- and diazepam-induced cognitive impairment without altering the animals' loco- 


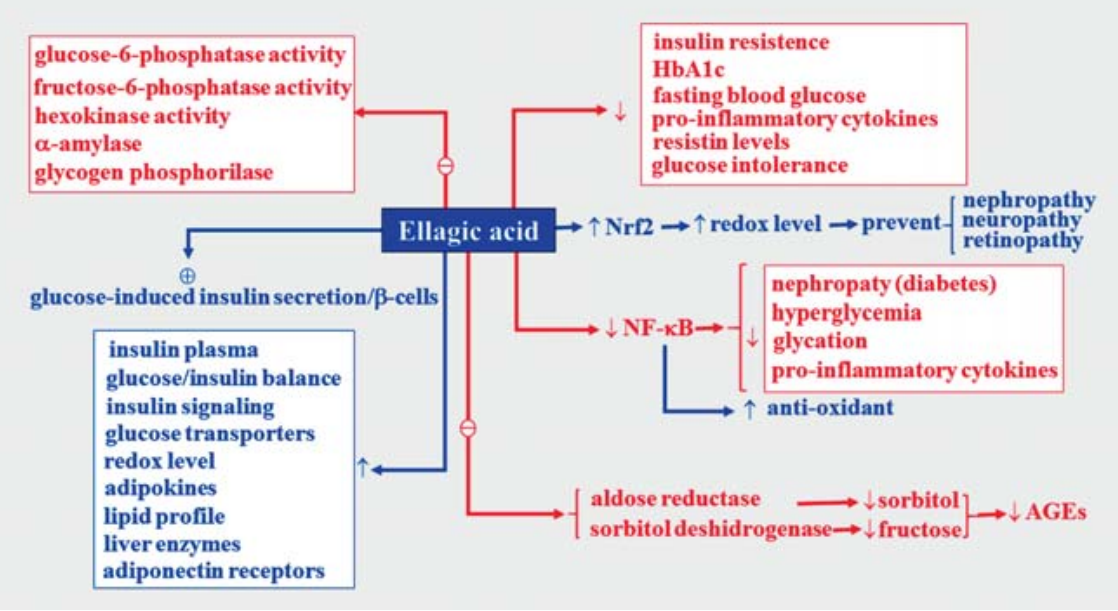

- Fig. 3 Antihyperglycemic effects of ellagic acid on glucose metabolism.

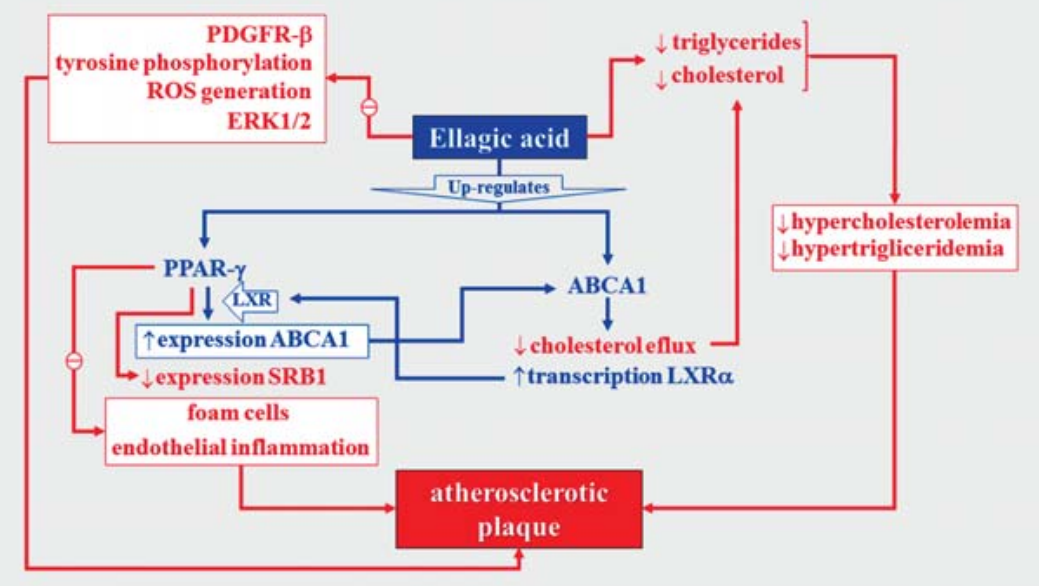

- Fig. 4 Effects of ellagic acid on lipid and cholesterol metabolism and their positive consequences on atherogenic formation.

motion. Bansal et al. [162] studied the effect of ellagic acid (17.5 and $35 \mathrm{mg} / \mathrm{kg}$, p. o.) on streptozotocin (3 mg/kg)-induced dementia in rats after bilateral intracerebroventricular injection in rats. After 28 days, ellagic acid both prevented the damage produced by streptozotocin and ameliorated the symptoms of dementia produced by this agent, probably by restoring the balance between cellular pro-oxidants and antioxidants in rat brains [162].

In their research, Sanadgol et al. [125] used C57BL/6 J mice in which a depletion of oligodendrocytes in the corpus callosum had been induced. They found that ellagic acid $(80 \mathrm{mg} / \mathrm{kg} / \mathrm{d}$, i. p., $4 \mathrm{wk}$ ) effectively reduced lesions via reduction of neuro-inflammation and toxic effects on mature oligodendrocytes with respect to the nontreated group (control). Treatment significantly downregulated the expression of IL-17 and upregulated the expression of IL-11 but had no effect on the expression of stromal cell-derived factor 1. Previously, these same authors had demonstrated that ellagic acid not only decreased the number of activated microglia cells, but also restricted the proliferation of these cells, thus lowering the concentration of microglial pro-inflammatory chemokines in the corpus callosum. They concluded that ellagic acid may constitute a suitable therapeutic agent for ameliorating brain damage in neuro-inflammatory diseases [163].

Nejad et al. $[164,165]$ proposed a model of global cerebral ischemia-reperfusion induced by bilateral vertebral and common carotid artery occlusion, which leads to disturbances in brain function. In this model, ellagic acid $(100 \mathrm{mg} / \mathrm{kg} / 10 \mathrm{~d}$, p. o.) improved both heart [164] and renal [165] function impaired by the global cerebral ischemia-reperfusion. The authors hypothesized that the acid's antioxidant properties may be responsible for these beneficial effects and noted ellagic acid's potential benefits in stroke victims. However, more specific studies are necessary to elaborate on this fairly simple hypothesis.

Farbood et al. [166] demonstrated the positive effects of ellagic acid in a model of traumatic brain injury induced by dropping a 200-g weight from a 2-m height through a free-falling tube onto the head of an anesthetized rat with a steel disk attached to its skull. Animals that received prior treatment with ellagic acid $(100 \mathrm{mg} / \mathrm{kg} / 7 \mathrm{~d}$, p. o.) showed lower levels of traumatic brain in- 
jury-induced memory loss and hippocampal long-term potentiation impairment. Pretreatment with ellagic acid also decreased the elevated content of IL-1 $\beta$, IL-6, and blood-brain barrier permeability in the brain normally produced during traumatic processes.

Liu et al. [167] tested an experimental model based on oxygenglucose deprivation and reoxygenation in primary cultured cortical neurons from rats. In this protocol, ellagic acid increased neuron viability, cell nuclear integrity, and the ratio of $\mathrm{Bcl}-2 / \mathrm{Bax}$ expression. In in vivo experiments, ellagic acid increased the number of $\mathrm{Bcl}$-2-positive cells while significantly decreasing both the volume of cerebrum infarction and the neurological deficit scores in the rats. The authors hypothesized that ellagic acid provides neuroprotection and that it could be used for treating nerve dysfunction, neurodegenerative disease, and aging processes.

Other researchers have focused on the potential of ellagic acid as a protective agent against neural damage in Parkinson's disease, with several studies examining this protective effect against free radical-induced damage. For example, Sarkaki et al. [168] tested the effects of ellagic acid $(50 \mathrm{mg} / \mathrm{kg}$, p. o.) on locomotion, pallidal local electroencephalography and the power of its frequency bands, as well as on cerebral antioxidant contents in a rat model of Parkinson's disease induced by 6-hydroxydopamine $(16 \mu \mathrm{g} / 2 \mu \mathrm{L})$ injected into the right medial forebrain bundle. The test compound restored the activity of glutathione peroxidase and superoxide dismutase in both the striatum and hippocampus tissues, significantly increasing malondialdehyde levels in both the striatum and hippocampus tissues in medial forebrain bundle-lesioned rats. It also ameliorated motor impairments and improved the electrophysiological performance in treated rats. These authors [166] had previously used the same experimental model to demonstrate that ellagic acid can improve induced motor impairments by reducing the higher levels of neuro-inflammatory biomarkers (TNF- $\alpha$ and IL-1 $\beta$ ) in lesioned rats while protecting the brain against free radical-induced neural damage. Using the same experimental model, Baluchnejadmojarad et al. [169] tested ellagic acid ( $50 \mathrm{mg} / \mathrm{kg} / \mathrm{d}, 1 \mathrm{wk}$ ) and obtained similar results; however, they also found that the compound lowered the striatal level of MAO-B in the treated group with respect to the 6-hydroxydopamine group but that both $\mathrm{Nrf2}$ and $\mathrm{HO}-1$ were increased at the striatal level. Treatment with ellagic acid also prevented loss of tyrosine hydroxylase-positive neurons within the substantia nigra pars compacta. These findings suggest that the neuroprotective effect of ellagic acid in this rat model of Parkinson's disease occurs via suppression of MAO-B, with its favorable influence being partly reliant on the estrogen receptor- $\beta / \mathrm{Nrf} 2 / \mathrm{HO}-1$ signaling cascade. Other studies on the effect of ellagic acid against MAO-B have determined its potency $\left(\mathrm{IC}_{50}=412.24 \mathrm{nM}\right)$ and the fact that its inhibitory activity against MAO is both competitive and noncompetitive [170].

Taken together, these results of both in vitro and in vivo experiments indicate that ellagic acid is of great interest for future studies, including on humans, with potential applications as a memory restorative agent in the treatment of dementia and other cognitive alterations observed in the elderly.

\section{Hepatoprotective Effects of Ellagic Acid}

Several studies have shown that ellagic acid has the potential to prevent or reduce toxicity in the liver by inhibiting NF- $K B$ activation and NO generation and by enhancing the cellular antioxidant system. García-Niño and Zazueta [50] reviewed the pharmacological activities of ellagic acid related to liver protection against a number of toxins including alcohol, $\mathrm{CCl}_{4}$, cisplatin, cyclosporine, rifampicin, isoniazid, mercury, and paracetamol, which impair both liver function and its architectural structure. The authors also described the molecular mechanisms involved, including free radical scavenging, regulation of cytokine production, phase I and II enzyme and lipid synthesis and degradation processes, as well as conservation of oligo element levels. Independently of this excellent review, we collected other relevant, but subsequently published, articles on this subject. For example, in their work, Keshtzar et al. [171] described ellagic acid's protective effects against liver toxicity induced by arsenic, a pro-oxidant hepatotoxic heavy metal and one of the most potent environmental toxins, as can be seen by its classification in group I of human carcinogens by the International Agency for Research on Cancer. Currently, exposure to arsenic is inevitable, contributing to chronic diseases through overproduction of free radicals and oxidative stress, mitochondrial dysfunction, ATP production impairment, and carcinogenicity. The effects of ellagic acid, a potent antioxidant, were tested at concentrations of $20-80 \mu \mathrm{M}$ against the toxicity induced by arsenic in mitochondria isolated from rat livers. The results indicated that this phenolic compound was able to reverse ROS generation and mitochondrial membrane damage, disrupt arsenic toxicity, and protect the mitochondria either directly through its antioxidant effect or indirectly by means of conserving the activity of mitochondrial complex II [171].

Ellagic acid's ability to interfere with phase I enzyme-catalyzed reactions has also been evaluated. For example, Siah et al. [172] analyzed the potential effects of ellagic acid on aldehyde oxidase, a phase-I cytosolic molybdenum-containing hydroxylase enzyme that is mainly active in the liver and participates in the metabolism of several aldehydes and nitrogen-containing molecules with biological functions. Phenolic compounds are known to interfere with aldehyde oxidase catalyzed reactions, interacting with specific drug-metabolizing enzymes and drug-food interactions with implications for human health. Specifically, ellagic acid was shown to inhibit aldehyde oxidase from guinea pigs in a noncompetitive mode of action and with an $\mathrm{IC}_{50}$ value of $14.5 \mu \mathrm{M}$, more potent than the specific inhibitor of aldehyde oxidase, menadione $\left(\mathrm{IC}_{50}=31.8 \mu \mathrm{M}\right)$. With regard to herbal-drug interactions mediated by CYP, the isoform CYP2D6 is responsible for the metabolism of nearly $25 \%$ of drugs. Thus, the effects of ellagic acid on the oral bioavailability of metoprolol was assessed in an in situ single pass intestinal perfusion study. In rats pretreated with the acid, improvements in both the plasma concentration and the area under the serum concentration-time profile were observed, along with a reduction in clearance. Ellagic acid significantly improved the oral bioavailability of metoprolol by inhibiting CYP2D6-mediated metabolism in the rat liver, suggesting that adverse herbal-drug interactions may occur when products containing ellagic acid are taken together with drugs that are CYP2D6 substrates [173]. 


\section{Cytotoxic, Antitumor, and Anticancer Effects of Ellagic Acid}

Ellagic acid is considered to be a promising new chemopreventive and/or chemotherapeutic agent. It has been shown to exert effects against human cancers, including prostate, colon, pancreatic, breast, ovarian, bladder, and glioblastoma cancers, as well as lymphoma. Its chemopreventive potential has been evaluated extensively, with results showing that ellagic acid exerts its anticarcinogenic effects through multiple pathways: by stopping tumor cell proliferation, inducing apoptosis, blocking DNA damage generated by oxidative stress and carcinogens, and interfering with inflammation, angiogenesis, and other process required for tumor progression and metastasis. Other indirect mechanisms associated with ellagic acid's anticancer properties include antivirus activity, heart and liver protection, radio-sensitizing and counter radio-resistance effects, and inhibition of glutathione S-transferase-induced drug resistance [174]. Liang et al. [175] evaluated the effects of ellagic acid on $\mathrm{Ca}^{2+}$ homeostasis in liver cells and found that it increases the intracellular $\mathrm{Ca}^{2+}$ concentration in HepG2 human hepatoma cells via a phospholipase C-dependent pathway. Moreover, ellagic acid (25-100 $\mu \mathrm{M})$ exhibited concentration-dependent cytotoxicity, which was partially prevented by the intracellular $\mathrm{Ca}^{2+}$ chelator 1,2-bis(2-aminophenoxy)ethane- $N$, $N, N^{\prime}, N^{\prime}$-tetraacetic acid-acetoxy methyl. Ellagic acid also killed HA22T and HA59T hepatoma cells, but had no effect on normal liver cells (AML12 mouse hepatocytes), providing evidence for its therapeutic potential in the treatment of hepatoma [175].

While some studies focus on the effects of ellagic acid, others analyzed its metabolites, which have been implicated in the compound's antiproliferative effect on different types of cancer cells. For example, the chemopreventive potential of ellagic acid and its metabolite urolithin A was studied in prostate cancer, which is initially dependent on androgens but then over time evolves to an androgen-independent phenotype, which is more resistant to secondary endocrine treatment and chemotherapy. The effects of ellagic acid and its metabolite on cell proliferation, cell cycle, and apoptosis were evaluated in the androgen-independent DU145 and PC-3 prostate cancer cell lines, with both compounds inhibiting cell proliferation in a dose-dependent manner, albeit with differences in the two cell lines and through different mechanisms of action. Whereas treatment with ellagic acid gave an antiproliferative $\mathrm{IC}_{50}$ of $14.5 \mu \mathrm{M}$ (at $96 \mathrm{~h}$ ) against PC-3 cells and an IC 50 of $23.0 \mu \mathrm{M}$ in the case of DU145 cells, treatment with urolithin A gave an $\mathrm{IC}_{50}$ value of $74.8 \mu \mathrm{M}$ (at $96 \mathrm{~h}$ ) but had no effect on the PC-3 cells. The two compounds also had different effects on the modulation of cell cycle regulatory proteins, with ellagic acid decreasing cyclin B1 and D1 expression and urolithin A inducing cdk1 (also called cell division control protein 2 or cdc2) phosphorylation at tyr-15 and increasing cyclin B1, which arrested the cell cycle in the $\mathrm{S}$ and $\mathrm{G}_{2} / \mathrm{M}$ phases, respectively. Ellagic acid also exhibited pro-apoptotic activity via a caspase dependent pathway. These effects may explain the synergistically inhibitory interaction between ellagic acid and its metabolite against PC-3 cell proliferation $[176,177]$. Independently of these mechanisms, there is a growing body of evidence that indicates that the multifunctional cytokine IL- 6 is involved in the transition of prostate cancer from an androgen-dependent to an androgen-independent state. Indeed, IL-6 interacts with different cellular regulatory signaling pathways, such as STAT3, Akt, and pERK1/2, which can either inhibit or stimulate various cancer cell lines. Treatment of PC-3 cells with ellagic acid $(30,50$, and $70 \mu \mathrm{M})$ led to increased IL-6 levels in culture supernatants in a dose-dependent manner and downregulated the expression of phosphorylated cellular proteins ( $p$ STAT3, p-Akt, and pERK1/2). Despite this increase in IL-6, which is probably due to heightened cancer cell resistance, and in agreement with previous studies, ellagic acid can be considered a potent antiproliferative agent against PC3 through the reduction of ERK1/2, Akt, and STAT3 cellular signaling proteins [178].

The combination of the three pomegranate constituents-ellagic acid, punicic acid, and luteolin-as well as the juice of this fruit are considered to be an alternative treatment for prostate cancer. Clinical trials have shown that pomegranate juice inhibits prostate cancer progression and prolongs the prostate specific antigen doubling time in prostate cancer patients [179]. The three constituents together ( $64 \mu \mathrm{g}$ each, i. p., once a day, $5 \mathrm{~d} / \mathrm{wk}, 8 \mathrm{wk}$ ) exhibited inhibitory effects on prostate cancer cells, angiogenesis, and metastasis. When tumor progression was monitored with bioluminescence imaging in an immunodeficiency mouse model in which luciferase-expressing human prostate cancer cells were subcutaneously injected close to the prostate, the three compounds inhibited the metastasis by blocking the stromal cell-derived factor 1 (also known as CXCL-12)/CXC chemokine receptor type 4 (also known as fusin or CD184) axis and interrupted the growth and metastasis of invasive Pten $^{-1-} ; \mathrm{K}_{\text {-ras }}{ }^{G 12 D}$ prostate tumors. They also inhibited angiogenic factors IL-8 and VEGF as well as their induced signaling pathways in endothelial cells [179]. Ellagic acid demonstrated anti-angiogenic activity in vivo in a hamster model of oral oncogenesis by inhibiting hypoxia inducible factor$1 \alpha$, VEGF, and its receptor (VEGFR2). This was accomplished by blocking the PI3K/Akt and MAPK signaling pathways and in vitro, by suppression of histone deacetylases in endothelial cell line ECV304 [180]. In the transgenic rat for adenocarcinoma of prostate model, ellagic acid suppressed tumor progression and induced apoptosis via caspase-3 activation after $10 \mathrm{wk}$ of treatment. This effect was confirmed in the human prostate cancer androgen dependent cell line LNCaP, where ellagic acid also induced apoptosis by augmenting the $\mathrm{Bax} / \mathrm{BCl}-2$ ratio and increasing cellcycle related proteins p21, p27, cdk-2, and cyclin E while decreasing cyclin D1 and cdk-1 [181].

Using colon cancer stem cells, Núñez-Sánchez et al. [182] evaluated the effect of a mixture of ellagic acid (5\%) and the gut microbiota-derived urolithins $A(85 \%)$ and C (10\%) detected in human colon tissues after intake of products with a high amount of ellagitannin, such as pomegranates and walnuts. The mixture not only inhibited aldehyde dehydrogenase activity, but also decreased the number $(26.3 \pm 3.8 \%)$ and size $(23.7 \pm 7.4 \%)$ of colonospheres in primary tumor cells from a patient with colorectal cancer, providing evidence for its potential role against colon cancer chemoresistance and relapse. In the case of ellagic acid (30 or $100 \mu \mathrm{g} / \mathrm{mL}$ ), the treatment of human colorectal carcinoma cells CaCo-2 and HCT-116 lowered cell proliferation through an apoptotic effect, arrested the cell cycle in the $G_{1}$ phase, and inhibited 
Akt phosphorylation (at Thr308 and Ser473), with subsequent downstream effects on the PI3K/Akt pathway, which plays a central role in colon tumorigenesis. Silencing of the $K$-ras (an early mutation in colorectal carcinogenesis) and treatment of transfected HCT-116 cells with ellagic acid inhibited cell proliferation and Akt phosphorylation at Thr308, confirming the role of activated $K$-ras in activating the PI3K/Akt pathway [183]. Microarray profile analysis of HCT-116 cells treated with ellagic acid $(100 \mu \mathrm{M})$ for $72 \mathrm{~h}$ aided in identifying differentially expressed genes affecting cellular functions such as proliferation, apoptosis, cell cycle, and angiogenesis [184]. In a leptin-enriched microenvironment $(200 \mathrm{ng} / \mathrm{mL})$, ellagic acid $(25$ or $50 \mu \mathrm{g} / \mathrm{mL})$ inhibited the proliferation of HCT-116 and $\mathrm{CaCo}-2$ cells, modulated the cell cycle, upregulated Bax, activated caspase-8, and decreased the expression of proliferating cell nuclear antigen, indicating a potential effect on obesity-related colon carcinogenesis [185]. Treatment of HCT-15 colon adenocarcinoma cells with ellagic acid (up to $60 \mu \mathrm{M}$ ) decreased cell proliferation and induced ROS production and apoptosis. It diminished cell viability and induced $\mathrm{G}_{2} / \mathrm{M}$ phase cell cycle arrest and also modulated alkaline phosphatase and lactate dehydrogenase activities, all of which indicate an antiproliferative and cytotoxic effect. Ellagic acid reduced the expression of the proliferation-associated markers proliferating cell nuclear antigen and cyclin D1 and blocked the PI3K/Akt pathway. Moreover, ellagic acid upregulated the expression of Bax, caspase-3, and cytochrome C while suppressing Bcl-2 [186].

In an experimental model of colon carcinogenesis induced by 1,2-dimethylhydrazine in rats, treatment with ellagic acid $(60 \mathrm{mg} / \mathrm{kg} / \mathrm{d}$, p. o.) led to beneficial effects such as reparation of negative effects on biochemical indexes, restoration of mitochondrial and membrane-bound enzyme activities, and a decrease in lysosomal enzymes [187]. Ellagic acid also seems to inhibit the growth, ability to repair, migration, and invasion of human pancreatic carcinoma PANC-1 cells in a dose dependent manner. Thus, PANC-1 cell tumor-bearing mice treated with ellagic acid had an increased survival rate, with inhibition of tumor growth through cell cycle arrest in the $\mathrm{G}_{1}$ phase; downregulation of COX2 , NF- $\mathrm{BB}$, and vimentin; and upregulation of E-cadherin [188].

In human breast cancer MCF-7 cells, ellagic acid $(10-40 \mu \mathrm{g} / \mathrm{mL})$ exerted its antiproliferative effects by arresting the cell cycle in $\mathrm{G}_{0} /$ $\mathrm{G}_{1}$ phase via modulation of the TGF- $\beta /$ Smads signaling pathway [189]. Ellagic acid improved the efficacy of the PI3K inhibitor GDC-0941, inhibiting cell growth, migration, and invasion in breast cell lines as well as reducing tumor induction and metastasis in vivo. In addition, the combination of ellagic acid and GDC-0941 induced apoptosis and reduced the Akt/mTOR activation in breast cancer cells [190]. Ellagic acid also has potential as a drug adjuvant for enhancing cancer radiotherapy due to its ability not only to improve apoptotic sensitivity on $y$-irradiated human breast cancer MCF-7 cells, but also to upregulate Bax and downregulate $\mathrm{Bcl}-2$, leading cells to undergo apoptotic death. While it was found to have a radio-protective effect on normal cell lines, combined treatment with ellagic acid (10 $\mu \mathrm{M})$ and doses of 2- and 4-Gy $y$ radiation on MCF-7 exhibited synergistic tumor cytotoxicity [191].

Ellagic acid enhances the sensitivity of cytostatic drugs by modulating various pathways in different ovarian cancer cell lines. Indeed, the use of ellagic acid $(3.2 \mu \mathrm{M})$ in the short-term treat- ment of the ovarian cancer A2780 cell line and its cisplatin-resistant subtype A2780CisR, obtained by intermittent treatment with cisplatin for 26 weekly cycles, led to a moderate reversal of cisplatin-chemoresistance [192]. Treatment of human endometrial cancer cells with ellagic acid ( $20 \mu \mathrm{M}, 48 \mathrm{~h})$ significantly inhibited ROS formation and regulated cytosolic $\mathrm{pH}$ and glycolytic flux. It downregulated sodium-hydrogen antiporter 1 expression and likewise decreased $\mathrm{Na}^{+} / \mathrm{H}^{+}$exchanger activity, cytosolic $\mathrm{pH}$, glucose uptake, and lactate release, all of which led to reprogramming and growth inhibition of tumor cells [193]. Ellagic acid has also been demonstrated to inhibit cervical cancer HeLa cells in a dose dependent manner $(2.5-10 \mu \mathrm{M})$ by blocking the Akt/mTOR signaling pathway through upregulation of IGFBP7 [194]. Treatment of HeLa cells with a combination of ellagic acid and curcumin ( $25 \mu \mathrm{M}$, they do not declare the proportion of each) enhanced their potential anticancer and antihuman papilloma virus properties, as evidenced by decreased levels of the human papilloma virus HPV-E6 oncoprotein [195].

The activity of mitomycin C, commonly used for treating bladder cancer, is enhanced by ellagic acid, which could thus serve as adjunct therapy for this type of cancer. Indeed, ellagic acid (1.25$40 \mu \mathrm{M}$, in vitro, and $40 \mathrm{mg} / \mathrm{kg}$, i. p., daily/15 d, in vivo) reduced the growth rate, infiltrative behavior, and tumor-associated angiogenesis of human bladder cancer xenografted mice. In addition, it inhibited both the tumor invasion and chemotaxis induced by VEGF-A. This phenolic acid also downregulated the expression of the receptor VEGFR-2, as well as the programmed cell-death ligand 1 [196]. In addition to these effects, ellagic acid may also be beneficial for the management of glioblastoma cancer, as demonstrated by Wang et al. [197]. These authors found that at 50 and $100 \mu \mathrm{M}$, the acid suppressed the cell viability of U251 glioblastoma cells and affected cell cycle progression by inducing cell cycle arrest in the $\mathrm{S}$ phase. Ellagic acid markedly inhibited the anti-apoptotic proteins $\mathrm{BCl}-2$ and survivin while enhancing caspase- 3 and the pro-apoptotic protein Bax. It upregulated MAPKs (JNK, ERK1/ 2, and p38) and the expression of DR4, DR5, and CHOP an endoplasmic reticulum stress-regulated protein, indicating the involvement of ROS-JNK/ERK signaling in cell death [197]. In addition, this phenolic compound (50 and $100 \mu \mathrm{M})$ also inhibited the viability and proliferation of U87 and U118 human glioblastoma cell lines, increasing the proportion of cells in the $\mathrm{S}$ phase. This activity was confirmed in vivo $(40 \mu \mathrm{g} / \mathrm{g}$ b.w., p.o. gavage daily, $5 \mathrm{~d} / \mathrm{wk}$, $4 \mathrm{wk}$ ) in glioblastoma xenografted mice. Ellagic acid suppressed tumor growth, upregulated E-cadherin expression, inhibited the expression of Snail, MMP-2 and MMP-9, Bcl-2, cyclin D1, cdk-2, and cdk-6, and blocked Akt and Notch signaling pathways [198].

Chronic lymphocytic leukemia is characterized by failed apoptosis, which in turn plays an important role in its resistance to conventional therapies. Pro-apoptotic signals such as oxidative stress, DNA damage, and mitochondrial membrane alterations all induce apoptosis. Salimi et al. [199] demonstrated that ellagic acid $(25 \mu \mathrm{M})$ was selectively able to induce ROS-mediated apoptosis in B-lymphocytes obtained from patients with chronic lymphocytic leukemia via the mitochondrial pathway. It did so by inducing failure of mitochondrial membrane potential, increasing mitochondrial swelling and cytochrome c release, all of which point to the acid's anticancer potential. 
Protein kinase $\mathrm{C}$ regulates many cellular processes, including apoptosis. Recent studies have reported novel and atypical isozymes of the protein kinase C subfamily to be mainly involved in cell proliferation, apoptosis, and differentiation; in fact, ellagic acid has been found to exhibit its anticarcinogenic activity through modulation of these isozymes. Using Dalton's lymphoma mice, Misra and Vinayak [200] demonstrated the anticarcinogenic effects of ellagic acid, which increased longevity and survival while decreasing tumor size, viability, and the proliferation of ascites cells. Treatment of lymphoma-bearing mice with 40,60 , or $80 \mathrm{mg} / \mathrm{kg}$ daily for 15 consecutive days induced apoptosis in the liver by promoting expression and activation of protein kinase $C \delta$ and caspase- 3 and also by inhibiting energy metabolism.

The low bioavailability of ellagic acid has inspired a number of studies focused on drug delivery systems in order to reach therapeutic concentrations in the systemic circulation and to increase efficacy. Wei et al. [201] used a nanomedicine against fibrotic stroma and tumor-promoting pancreatic stellate cells. It consisted of 9-nm human serum albumin-ellagic acid and human serum albumin-paclitaxel complexes co-encapsulated into thermosensitive liposomes that improved drug perfusion and led to tumor growth inhibition and apoptosis. When ellagic acid (up to $100 \mu \mathrm{M}$ ) was encapsulated into the polymer-based nanoparticles (diameter average $150-300 \mathrm{~nm}$ ) poly D-L-lactide-co-glycolide decorated with chitosan and polyethylene glycol, the resulting poly D-L-lactide-co-glycolide-chitosan-polyethylene glycol potentiated apoptosis-mediated cell death in HepG2 human hepatoma cells [202]. Ellagic acid-encapsulated $(2 \mu \mathrm{M})$ nano-sized metalla-cages exerted anticancer activity by inhibiting the growth of cancer cells through modulation of the granulocyte-colony stimulating factor at gene and protein expression levels and in macrophages regulated by activation of normal T-cell expressed and secreted protein [203].

The principal studies in vitro of effect of ellagic acid on different cancerous cell lines are summarized in > Table 2.

\section{Ellagic Acid and Skin Protection}

UV radiation causes oxidative stress through production of ROS, which disrupt the endogenous antioxidative system of the skin cells and may lead to skin inflammatory disorders, depigmentation, photoaging, and carcinoma. Several studies have described the potential photoprotective effects of ellagic acid, suggesting its promising potential as a food supplement and/or in the preparation of skin care products for the prevention or treatment of skin disorders. Indeed, the antioxidative effect of ellagic acid against UV-A- and UV-B-induced oxidative stress on human keratinocyte $(\mathrm{HaCaT})$ cells and human dermal fibroblasts has already been demonstrated. Ellagic acid $(1-10 \mu \mathrm{M})$ increased in a dosedependent manner the viability of UV-B-exposed keratinocytes and fibroblasts, attenuated MMP secretion, and raised collagen levels in dermal fibroblasts. Ellagic acid thus exhibited photoprotective effects on skin wrinkle formation resulting from collagen breakdown through increasing MMP production. Moreover, topical application of the acid $(10 \mu \mathrm{M})$ to the dorsal skin of SKH-1 hairless mice exposed to chronic UV-B radiation $\left(100 \mathrm{~mJ} / \mathrm{cm}^{2}, 8 \mathrm{wk}\right)$ attenuated wrinkle formation and epidermal thickness while also decreasing the accumulation of inflammatory cytokines such as IL-1 $\beta$ and IL-6 and the expression of ICAM-1 [119]. Ellagic acid $(5 \mu \mathrm{M})$ also reduced pro-inflammatory mediators and significantly increased IL-10 expression in HaCaT under UV-B radiation [204]. In addition, the photoaging protection was confirmed in cultured fibroblasts when cells were exposed to ellagic acid $(5,15,30 \mu \mathrm{M}$ prior to UV-B irradiation [70 $\left.\mathrm{mJ} / \mathrm{cm}^{2}\right]$ ). It decreased both ROS levels and MMP-2 production and also restored total glutathione levels and superoxide dismutase activity in a concentration-dependent manner, partly by upregulating Nrf2 [82]. Pre-treatment of irradiated (UV-A, $20 \mathrm{~J} / \mathrm{cm}^{2}$ ) HaCaT cells with ellagic acid (25$75 \mu \mathrm{M})$ inhibited cytotoxicity and suppressed ROS production and lipid peroxidation. It also inhibited UV-A-induced apoptosis by blocking DNA strand breaks, downregulating activation of caspase-3, and dysregulating $\mathrm{Bcl}-2$ and Bax expression. These effects were associated with a notable rise in $\mathrm{HO}-1$ or superoxide dismutase via upregulation of the oxidative stress marker $\mathrm{Nrf2}$ and downregulation of the Kelch-like ECH-associated protein-1. These findings add further support for ellagic acid's protective effects against UV-A-induced skin damage [83].

Due to ellagic acid's poor biopharmaceutical properties, low solubility, and low permeability, various formulations have been developed. As a plausible agent for manufacturing antiphotoaging cosmetics, for example, the acid should be incorporated into a topical formulation because it permeates the skin barrier to reach the viable epidermis and dermis layers, thus helping to avoid or delay UV radiation damage. Pomegranate peel polyphenols including ellagic acid were delivered to the deeper skin layers by applying nanoemulsions of the ethyl acetate fraction prepared with pomegranate seed oil onto the skin [205]. Previously, a topical ointment prepared with polyethylene glycol and 5\% standardized pomegranate rind extract containing ellagic acid (13\%) was developed for release and skin permeation studies and was found to exhibit acceptable physicochemical properties [206]. When the wound healing activities of this ointment were compared with the equivalent amount of ellagic acid $(0.65 \%)$, the latter was less effective in inhibiting neutrophil infiltration and collagen augmentation in rat skin [207]. However, both products applied topically exhibited similar anti-inflammatory effects against a mouse model of contact dermatitis [92]. Another dermal delivery system that was developed involved ellagic acid-loaded niosomes. Those prepared with the mixture Span 60 and Tween 60 (2:1), with 15\% polyethylene glycol 400 as solvent, exhibited the highest percentage of both entrapment efficacy as well as delivery of ellagic acid to human epidermis and dermis [208].

Although melanin protects from UV damage, its excessive production causes hyperpigmentation. While hydroquinone is a well-known benchmark product for treating hyperpigmentation, its adverse effects make the search for alternative agents necessary. Ellagic acid is considered to be a useful depigmentation agent in the treatment of hyperpigmentation disorders because it interferes with the melanin biogenesis pathway in which tyrosinase catalyzes the hydroxylation of monophenols to o-diphenols and their subsequent oxidation to the unstable o-quinones, which are then converted to melanins. In their research, Ito and Wakamatsu [209] determined the differences between leukoderma-inducing phenols and phenolic skin whitening tyrosinase in- 
- Table 2 Resume of ellagic acid effects on different kind of cancer cell lines.

\begin{tabular}{|c|c|c|c|}
\hline Cancer type & Cell line & Mechanism of action & References \\
\hline Breast & MCF-7 & $\begin{array}{l}\text { Cell cycle arrest } \mathrm{G}_{0} / \mathrm{G}_{1} \text { via TGF- } \beta / \mathrm{Smads} \text { pathway } \\
\text { Upregulate Bax and downregulate } \mathrm{Bcl}-2 \\
\uparrow \text { synergistic cytotoxicity and apoptotic sensitivity on } \gamma \text {-irradiated cells } \\
\downarrow \text { Akt/mTOR activation }\end{array}$ & [189-191] \\
\hline Cervical & HeLa & Upregulate IGFBP7and block Akt/mTOR pathway & [194] \\
\hline \multirow[t]{3}{*}{ Colon } & Stem cells & $\downarrow$ Number and size colonospheres & [182] \\
\hline & $\begin{array}{l}\text { Caco-2 } \\
\text { HCT-116 }\end{array}$ & $\begin{array}{l}\text { Cell cycle arrest } G_{1} \\
\text { Upregulate Bax, } \uparrow \text { caspase } 8 \\
-\downarrow \text { PI3K/Akt pathway }\end{array}$ & {$[183,185]$} \\
\hline & HCT-15 & $\begin{array}{l}\downarrow \text { Cell proliferation and induces cycle arrest } \mathrm{G}_{2} / \mathrm{M} \\
\text { Upregulate Bax, caspase } 3 \text {, cytochrome } \mathrm{C} \\
\text { Downregulate Bcl-2 and cyclin D1, } \\
\text { Blocked PI3K/Akt pathway }\end{array}$ & {$[186]$} \\
\hline Endometrial & Ishikawa & $\downarrow$ ROS, cytosolic pH and glycolytic flux & [193] \\
\hline \multirow[t]{2}{*}{ Glioblastoma } & U251 & $\begin{array}{l}\text { Upregulate Bax and caspase } 3 \\
\text { Upregulate MAPKs, and expression DR4, DR5, CHOP } \\
\downarrow \text { BCl-2 and survivin }\end{array}$ & [197] \\
\hline & $\begin{array}{l}\text { U87 } \\
\text { U118 }\end{array}$ & Cell cycle arrest $S$ & [198] \\
\hline \multirow[t]{2}{*}{ Liver } & HepG2 & $\uparrow\left[\mathrm{Ca}^{2+}\right]$ i via phospholipase $\mathrm{C}$ & [175] \\
\hline & $\begin{array}{l}\text { HA22T } \\
\text { HA59T }\end{array}$ & Cytotoxicity. No effect on normal liver cells (AML12) & {$[175]$} \\
\hline Ovarian & A2780 & $\downarrow$ Cisplatin chemoresistance & [192] \\
\hline Pancreas & PANC-1 & $\begin{array}{l}\downarrow \text { Cell growth, migration, invasion } \\
\text { Cell cycle arrest } \mathrm{G}_{1} \\
\text { Downregulate COX-2, NF- } \kappa \text { B and vimentin } \\
\text { Upregulate E-cadherin }\end{array}$ & [188] \\
\hline \multirow[t]{4}{*}{ Prostate } & DU145 & $\begin{array}{l}\text { Anti-proliferative } \mathrm{IC}_{50}=23 \mu \mathrm{M}(96 \mathrm{~h}) \\
\text { Cell cycle arrest } \mathrm{S} \\
\downarrow \text { Cyclin B1 and D1 expression }\end{array}$ & {$[176,177]$} \\
\hline & PC-3 & $\begin{array}{l}\text { Anti-proliferative } \mathrm{IC}_{50}=14.5 \mu \mathrm{M}(96 \mathrm{~h}) \\
\text { Cell cycle arrest S } \\
\downarrow \text { Cyclin B1 and D1 expression } \\
\uparrow \text { IL-6 levels } \\
\text { Downregulate p-STAT3, p-Akt, pERK1/2 }\end{array}$ & [176-178] \\
\hline & ECV304 & $\downarrow$ Histone deacetylases & [180] \\
\hline & LNCaP & $\begin{array}{l}\uparrow \text { Bax, p21, p27, cyclin E, cdk-2 } \\
\downarrow \text { Bcl-2, cyclin D1,cdk-1 }\end{array}$ & [181] \\
\hline
\end{tabular}

hibitors using spectrophotometric $(420 \mathrm{~nm})$ and HPLC analyses after reduction with $\mathrm{NaBH}_{4}$ for detecting the corresponding catechols. They demonstrated that while the leukoderma-inducing phenols were readily oxidized by tyrosinase to form o-quinones, the latter were not. Thus, rather than being a tyrosinase inhibitor, ellagic acid can act as an alternative tyrosinase substrate to be oxidized to form o-quinones and semiquinones, which may then react with nucleophilic compounds. As a powerful antioxidant, ellagic acid is capable of modifying the redox status of the cell and may thus reduce these reactive molecules (the ratio of the antioxidant concentration necessary to decrease the initial concentration of the ABTS to $50 \%$, is 20 for ellagic acid, five times greater than that of ascorbic acid), inhibiting the melanogenesis process [210]. This should be taken be into account when ellagic acid is used as an ingredient in whitening creams and other cosmetics. The skin-lightening ability, tolerability, and safety profile of a novel alternative formulation containing ellagic acid was assessed against other active compounds in a single-blind study $(n=82)$. The results were similar for the ellagic acid formulation and the standard cream (hydroquinone + tretinoin), prompting the authors to claim that the former could be used as a benchmark to give dermatologists a frame of reference for expected efficacy [211]. Previously, the same efficacy and tolerance were observed in comparing a topical formulation containing ellagic acid $(0.5 \%)$ and salicylic acid $(0.1 \%)$ versus hydroquinone $(4.0 \%)$, with similar results on skin depigmentation [212]. 


\section{Cardiovascular Effects}

In their review of the effects of ellagic acid on vascular health, Larrosa et al. [8] noted the extreme difficulty in establishing the systemic potential of the compound due to its low bioavailability. This property can only be justified either by an effect in situ or as a consequence of the acid's antioxidant activity, which hampers the oxidation of other bioactive compounds, such as vitamins or fatty acids. However, recent studies have been conducted using various in vivo experiments to elucidate the activity of ellagic acid in cardiovascular disease. For example, ellagic acid $(10 \mu \mathrm{M})$ accelerated the rate of relaxation and the rate of $\mathrm{Ca}^{2+}$ transient decay in streptozotocin-treated mice, with the former effect being completely inhibited by the sarco-endoplasmic reticulum $\mathrm{Ca}^{2+}$-ATPase inhibitor cyclopiazonic acid. This indicates not only that diabetes mellitus-induced myocardial diastolic dysfunction is partly caused by reduction of sarco-endoplasmic reticulum $\mathrm{Ca}^{2+}-\mathrm{ATP}_{\text {ase }}$ function, but also that it can be ameliorated by ellagic acid and other activators [213]. Ellagic acid exerts a cardioprotective effect against $\mathrm{As}_{2} \mathrm{O}_{3}$ toxicity, a consequence of its antioxidant properties, which in this case enhance the endogenous antioxidant system [214]. It also protects against doxorubicin-induced cardiotoxicity in mice [215]. Indeed, intake of ellagic acid $(0.25,0.5$, and $1 \%$, in feed, $8 \mathrm{wk}$ ) dose-dependently increased the content of this compound in cardiac tissue and preserved glutathione content while lowering ROS and malondialdehyde levels; it also reduced xanthine oxidase activity. Ellagic acid ( 0.5 and $1 \%$ ) lowered some of the experimental results that had been increased by administration of doxorubicin, such as lactate dehydrogenase activity, creatine phosphokinase activity, caspase- 3 activity, and cleaved caspase- 3 formation, while suppressing both p-p38 expression as well as the activity and protein levels of NF- $K$ B. At $1 \%$, ellagic acid downregulated $\mathrm{p}$-ERK $1 / 2$ expression. These findings suggest that ellagic acid is a potent cardiac protective agent against doxorubicin [215].

At the higher dose, it also downregulated p-ERK1/2 expression [215]. Ellagic acid was also shown to have cardioprotective effects in rats treated with isoproterenol to induce myocardial infarction. Administration of ellagic acid (7.5 and $15 \mathrm{mg} / \mathrm{kg}$, p.o.) modified various biochemical parameters, including serum iron, plasma iron binding capacity, uric acid, glycoprotein, and electrolytes. It also returned the various hematological parameters to near normal levels, down from the increased levels brought on by the administration of isoproterenol $(100 \mathrm{mg} / \mathrm{kg}, 2 \mathrm{~d})$ [216]. Using the same doses, administration method, and experimental protocols, these authors also described ellagic acid's protective effects against isoproterenol-induced arrhythmias, hypertrophy, and lipid peroxidation during myocardial infarction in rats [217]. In addition, ellagic acid ( $15 \mathrm{mg} / \mathrm{kg}, 10 \mathrm{~d}$, p. o.) exhibited cardioprotective effects on $\mathrm{CaCl}_{2}$-induced arrhythmias in a rat stress model, reducing the incidence rates of premature beats, fibrillation, and ventricular tachycardia induced by $\mathrm{CaCl}_{2}(140 \mathrm{mg} / \mathrm{kg}$, i. v.) [218].

The effects of ellagic acid on hypertension have been analyzed by many different research groups. For example, Berkban et al. [69] studied its effect on the oxidative stress and hypertension induced by L-NAME in male Sprague-Dawley rats. In these experiments, ellagic acid ( 7.5 or $15 \mathrm{mg} / \mathrm{kg}$, p. $0 ., 5 \mathrm{wk}$ ) attenuated hypertension, prevented oxidative stress, and restored NO bioavail-

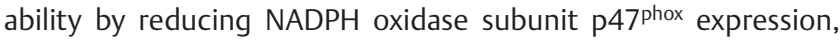
which is responsible for increased vascular superoxide radical production in L-NAME hypertensive rats via upregulation of the NADPH oxidase subunit $\mathrm{p} 47^{\text {phox }}$. Ellagic acid reduced both the systolic and diastolic pressures elevated by L-NAME $(40 \mathrm{mg} / \mathrm{kg} /$ day, $5 \mathrm{w}$ ) from $199 / 140 \mathrm{mmHg}$ to $168 / 114$ and $165 / 111 \mathrm{mmHg}$ at doses of $7.5 / 15 \mathrm{mg} / \mathrm{kg}$, respectively [69]. In an in vitro study, Olgar et al. [219] had previously demonstrated that ellagic acid can modify ionic and mechanical properties of isolated rat ventricular myocytes, starting at nanomolar concentrations. It dose-dependently reduced Ca currents with an $\mathrm{EC}_{50}$ value of $23 \mathrm{nM}$ and exerted negative inotropic effects through activation of the NO synthase-guanylyl cyclase-cGMP pathways, all without affecting the inactivation and reactivation parameters [219].

\section{Other Properties of Interest of Ellagic Acid}

Ellagic acid has been described as antibacterial [220], antiviral [221], and antimalarial [222]. The antibacterial properties of ellagic acid were described in various reviews, such as that by Howell and D'Souza [223], which cited the activity of pomegranate juice and established ellagic acid as a potential active principle, a claim that was bolstered by Shaygannia et al. [224]. A selective review was carried out by Chinsembu [225], who reviewed the effects of natural products against tuberculosis and included ellagic acid as a putative active compound against mycobacteria.

Tran et al. [226] described the effect of ellagic acid (from Aronia melanocarpa [Michx.] Elliott, Rosaceae) against the influenza virus in the cytopathic effect reduction assay with an $\mathrm{EC}_{50}$ value between 0.14 and $0.27 \mu \mathrm{M}$ against different virus strains. It inhibited hepatitis $C$ virus protease activity, with an $\mathrm{IC}_{50}$ of $56.3 \mu \mathrm{M}$ $[227,228]$, and inhibited virus replication with an $\mathrm{EC}_{50} \sim 60 \mu \mathrm{M}$ [218]. When Park et al. [229] studied the effect of ellagic acid against influenza virus (H1/K09) in a replication inhibition assay in MDCK cells, they observed that it reduced virus replication in the lungs of infected mice (about $50 \%$ ) with respect to nontreated mice [229].

As commented above, ellagic acid showed activity in vitro against different Plasmodium falciparum strains, with an $\mathrm{IC}_{50}$ range of 105-330 nM. It also exhibited in vivo activity against Plamodium vinckei petteri, showing suppressive, curative, and prophylactic murine properties. Ellagic acid has a high therapeutic index when administered i. p., but when administered p. o., its antimalarial efficacy is limited. For this reason, its pharmacokinetic properties should be enhanced [222]. Other studies have described the synergy between ellagic acid and several antimalarial drugs, which could allow for dose reduction in the treatment of malaria, with the concomitant reduction in potential side effects [230].

Ellagic acid showed neither acute toxicity nor chronic effects after its administration to mice. Indeed, treatment with ellagic acid up to $5000 \mathrm{mg} / \mathrm{kg}$ induced no toxic signs and, after repeated oral administration $(1000 \mathrm{mg} / \mathrm{kg} / \mathrm{d}$ for $28 \mathrm{~d}$ ), no obvious toxic symptoms affecting vital organs (liver and spleen) were observed [228]. Likewise, doses of $100 \mathrm{mg} / \mathrm{kg} / \mathrm{d}$ administered i. p. did exhibited no toxicity in mice [222]. 


\section{Clinical Trials with Implications for Ellagic Acid Treatment}

A limited number of relevant clinical studies with ellagic acid have been conducted. Some were carried out with medicinal plants containing this compound as well as ellagitannins and their metabolites, urolithins, which are produced by the gut microbiota after metabolizing ellagitannins and ellagic acid. Núñez-Sánchez et al. [231] studied the possible effect of these metabolites in colorectal cancer patients ( $n=52)$ after they had been given pomegranate extract $(900 \mathrm{mg} / \mathrm{d}, 15 \mathrm{~d})$, analyzing the presence of these metabolites in the urine or tissue of normal and malignant colons. Ellagic acid was detected in colon tissue both in free form and as conjugates. Samples from colorectal cancer patients who had received $291 \mathrm{mg} / \mathrm{g}$ of free ellagic acid showed $649 \mathrm{ng} / \mathrm{g}$ in normal tissue and $195 \mathrm{ng} / \mathrm{g}$ in malignant tissue.

In addition, various clinical trials have been conducted on cancer and human papillomavirus infection, but these have mostly been carried out with mixtures or supplementation together with other substances, making it difficult to establish the active principle responsible for the specific pharmacological effect. For example, in a randomized, controlled trial (NCT02263378), the authors evaluated the effects of a supplement with ellagic acid plus Annona muricata L. (Annonaceae) on the immune response against papillomavirus infection, but no study results were posted [232]. Other clinical trials analyzed dietary intervention in follicular lymphoma using various agents in which pomegranate juice with ellagic acid was included [233], while others examined the effect of pomegranate extract supplementation in colorectal cancer patients [234]. While no results were posted for either trial, the effects can most likely be assigned to the metabolites (urolithins) of ellagitannins and ellagic acid.

Another series of studies focused on skin hyperpigmentation in humans and the potential of ellagic acid to protect against different agents. For example, Ertam et al. [235] analyzed the effect of synthetic ellagic acid $(n=10)$ and plant extracts containing ellagic acid on thirty patients with melasma in a randomized, prospective, open-label study. Of the 10 patients who received treatment with synthetic ellagic acid, nine completed the study; of these, eight showed decreases in melanin levels after treatment with the acid. In addition, formulations prepared with plant extracts containing $1 \%$ ellagic acid $+1 \%$ plant extract demonstrated the same efficacy against melasma as the formulations prepared with synthetic ellagic acid (1\%). Previously, Kasai et al. [236] had conducted a double-blind, placebo-controlled trial for evaluating the protective and ameliorative effects of a pomegranate extract rich in ellagic acid on skin pigmentation after ultraviolet irradiation. Healthy female volunteers ( $n=30 \times$ three groups) were given either ellagic acid at a high dose $(200 \mathrm{mg} / \mathrm{d})$, a low dose $(100 \mathrm{mg} / \mathrm{d})$, or a placebo control $(0 \mathrm{mg} / \mathrm{d})$. The results demonstrated that oral administration of ellagic acid-rich pomegranate extract inhibits the effects caused by UV on pigmentation in human skin. In 2013, Dahl et al. [212] carried out a double-blind clinical study lasting $12 \mathrm{wk}$ to compare the effect of a topical product containing ellagic acid $(0.5 \%)$ and salicylic acid $(0.1 \%)$ with another containing hydroquinone (4\%), both applied twice daily. They randomly assigned 54 multi-ethnic subjects into two groups and found that the effect of ellagic acid was comparable to that of the standard drug used for skin depigmentation but with better physical and esthetic characteristics.

A single-center, investigator-blinded, 12-wk study was developed by Draelos et al. [211], who divided 82 subjects (7 male, 75 female) between 25 and 60 y of age into two balanced groups of 41 subjects each. They compared the skin-lightening ability, tolerability, and safety profile of a novel formulation containing ellagic acid, hydroxyphenoxy propionic acid, yeast extract, and salicylic acid (formula percentages were not given) and compared the results with those of a standard treatment (cream with $4 \%$ hydroquinone and $0.025 \%$ tretinoin) applied nightly. The groups were balanced for age, severity of dyspigmentation, and Fitzpatrick skin types. The facial dyschromias deemed appropriate for inclusion were mottled hyperpigmentation and lentigines, but not melasma. The results were similar for both formulas, but use of the novel preparation avoided administration of more aggressive compounds, such as tretinoin, thus suggesting the valuable potential of this new formulation in the treatment of skin dyspigmentation [211].

\section{Pharmacokinetic Properties of Ellagic Acid}

The intake of ellagic acid in humans around the world is varied and depends on both the region and the life-style. It can usually be obtained directly in its free form or as ellagitannins, which are hydrolyzed by the enzyme ellagitannase (ellagitannin acyl hydrolase) to release ellagic acid and other relevant metabolites [237]. With respect to the pharmacokinetic properties of ellagic acid, very few studies have been carried out, especially in humans. For example, in order to elucidate the acid's pharmacokinetic properties, Lei et al. [238] used HPLC to analyze the presence of ellagic acid after oral administration of pomegranate leaf extract $(0.8 \mathrm{~g} / \mathrm{kg})$. They observed an open, two-compartment system with a lag time and a plasmatic $C_{\max }$ of $213 \mathrm{ng} / \mathrm{mL}(0.55 \mathrm{~h})$ after oral administration of the extract, with poor absorption and rapid elimination.

Murugan et al. [239] performed an in vivo study with Wistar rats to investigate the pharmacokinetics of an ellagic acid-phospholipid complex (equivalent to $80 \mathrm{mg} / \mathrm{kg}$ of ellagic acid) and observed that the serum concentration of ellagic acid obtained from the complex was higher $\left(C_{\max }=0.54 \mu \mathrm{g} / \mathrm{mL}\right)$ than when the equivalent dose of the free form $(80 \mathrm{mg} / \mathrm{kg})$ was used $\left(C_{\max }=0.21 \mu \mathrm{g} /\right.$ $\mathrm{mL}$ ); moreover, the plasmatic concentration of the complex was maintained over a long period of time [239]. In 2014, Yan et al. [240] analyzed the pharmacokinetics and tissue distribution of ellagic acid in Sprague-Dawley rats. The compound was separated, detected, and quantified in plasma using a solid phase extraction step prior to reversed-phase ultra-performance liquid chromatography. Mass spectrometric detection was carried out with heated electrospray ionization (negative mode) and multiple ion monitoring. After oral administration of ellagic acid ( $50 \mathrm{mg} / \mathrm{kg}$ ), plasma levels peaked at about $30 \mathrm{~min}$, with a $C_{\max }$ value of $93.6 \mathrm{ng} / \mathrm{mL}$ $(0.31 \mu \mathrm{M})$. The area under the curve $\left(A U C_{0-\infty}\right)$ of the concentration-time profile was $457.2 \mathrm{ng} / \mathrm{mL} \times \mathrm{h}$, indicating that this compound exhibits extremely poor absorption after oral administration. Ellagic acid followed a pharmacokinetic profile fitted to a 
two-compartment model with a $t_{1 / 2 \alpha}=0.25 \mathrm{~h}$ and $t_{1 / 2 \beta}=6.86 \mathrm{~h}$. Other relevant parameters were $C L=109.3 \mathrm{~L} / \mathrm{h} / \mathrm{kg}, \quad A U C_{0-\mathrm{t}}$ $252.0 \mathrm{ng} / \mathrm{mL} \times \mathrm{h}, K_{10}=0.54 \mathrm{~h}^{-1}, K_{12}=1.90 \mathrm{~h}^{-1}, K_{21}=0.47 \mathrm{~h}^{-1}$, and $K a=14.52 \mathrm{~h}^{-1}$. Ellagic acid was detected in all the various tissues examined, including kidneys, liver, heart, lungs, and brain, with the highest levels found in the kidneys (about $250 \mathrm{ng} / \mathrm{g}$ at $0.5 \mathrm{~h}$ and $180 \mathrm{ng} / \mathrm{g}$ at $2 \mathrm{~h}$ ) and liver (about $45 \mathrm{ng} / \mathrm{g}$ at $0.5 \mathrm{~h}$ and $70 \mathrm{ng} /$ $\mathrm{g}$ at $2 \mathrm{~h}$ ). Although the values observed in this study differed from those of prior reports, it is also true that the doses and the experimental protocols were different.

The literature contains several clinical trials, but the protocols and number of patients are usually limited. For example, Seeram et al. [241] administered $180 \mathrm{~mL}$ pomegranate juice containing $25 \mathrm{mg}$ of ellagic acid and $318 \mathrm{mg}$ of ellagitannins (expressed as punicalagins) to one sole male subject. The maximum plasmatic concentration $(31.9 \mathrm{ng} / \mathrm{mL})$ was obtained after $1 \mathrm{~h}$ post-ingestion but was completely eliminated at $4 \mathrm{~h}$; however, this preliminary study is hardly conclusive due to the fact that only one case was analyzed. A year later, Stoner et al. [242] carried out a clinical trial with eleven subjects to determine the safety/tolerability of ellagic acid and other phenolic compounds after administration of black raspberries ( $45 \mathrm{~g} / \mathrm{d}$ for $7 \mathrm{~d}$ ). Samples of blood and urine were collected on days 1 and 7, with analyses showing that the maximum concentration of ellagic acid in plasma occurred at $1-2 \mathrm{~h}$, while in urine it appeared from 0 to $4 \mathrm{~h}$; nevertheless, upon quantification, it was demonstrated that less than $1 \%$ was absorbed and excreted in urine.

Various hypotheses can be made with the data known to date [156]. After ingestion of ellagic acid, there is a small proportion of free compound that can be absorbed in the stomach while the rest of it is absorbed in the small intestine [243]. In contrast, ellagitannins are resistant to gastric metabolism; their hydrolysis occurs in the small intestine at a neutral to slightly basic $\mathrm{pH}$, giving free ellagic acid that can be taken up in the small intestine. As there are no specific transporters across the gut epithelium for this compound, this process must occur through passive diffusion due to a concentration gradient [244]. For this reason, the presence of ellagic acid in plasma depends on its ratio to ellagitannins present in the specific food or medicinal plant [156]. In the case of pomegranate juice with $318 \mathrm{mg}$ ellagitannins and $25 \mathrm{mg}$ free ellagic acid, the plasmatic values of the free form reached a $C_{\max }$ of $32 \mathrm{ng} / \mathrm{mL}(0.106 \mu \mathrm{M})$ at $1.0 \mathrm{~h}$ [241]. When the same dose of pomegranate juice with same amount of ellagitannins $(318 \mathrm{mg})$ but only $12 \mathrm{mg}$ of free ellagic acid was assayed, the result was a $C_{\max }=18 \mathrm{ng} / \mathrm{mL}(0.06 \mu \mathrm{M})$ [245], whereas a similar study with a pomegranate extract containing $330 \mathrm{mg}$ ellagitannins and $22 \mathrm{mg}$ free ellagic acid gave a $C_{\max }=33 \mathrm{ng} / \mathrm{mL}(0.11 \mu \mathrm{M})$ at $1 \mathrm{~h}$ for this compound [246]. González-Sarrías et al. [247] described the absorption saturation in the small intestine when high doses of ellagic acid were used. Indeed, in a crossover study with humans who received either $130 \mathrm{mg}$ punicalagin plus $524 \mathrm{mg}$ free ellagic acid (high dose) or $279 \mathrm{mg}$ punicalagin plus $25 \mathrm{mg}$ free form (low dose), the authors observed that the high dose of the free form showed no enhanced bioavailability with respect to the low dose [247]. Another interesting hypothesis about the data obtained from pharmacokinetic studies on ellagic acid is that the primary absorption occurs in the stomach and the upper part of the small intestine (short $T_{\max }$ ) and that the rapid elimination is due to an efficient first-pass metabolism and a weak enterohepatic recirculation [156]. The unabsorbed ellagic acid and ellagitannins are metabolized by gut microbiota in the colon to urolithins [248], whereas the absorbed ellagic acid is converted to methyl esters, dimethyl esters, and glucuronides, which are eliminated through urine $1-5 \mathrm{~h}$ after ingestion [156, 245, 246, 249].

Several derivatives or new formulations have been proposed for increasing the pharmacokinetic properties and, in parallel, the pharmacological activity of ellagic acid, as seen in the study mentioned above. For example, whereas Wei et al. [201] used a nanomedicine (thermosensitive liposomes with co-encapsulated $9 \mathrm{~nm}$ human serum albumin-ellagic acid + human serum albumin-paclitaxel complexes) in their research, Abd-Rabou and Ahmed [202] encapsulated ellagic acid into the polymer-based nanoparticles (150-300 nm) poly D-L-lactide-co-glycolide, while Dubey et al. [203] used capsules of ellagic acid in nano-sized metalla-cages. In all these cases, there was a clear increase in activity that prompted the various authors to propose that these modifications be employed to increase ellagic acid's therapeutic utility as an anticancer agent. In the case of skin protection, some authors proposed the use of nanoemulsions [205], ointment (polyethylene glycol) $[92,206,207]$, or niosomes (Span 60-Tween 60, 2:1 and 15\% polyethylene glycol 400) [208]. Again, all these novel formulations led to clear advantages, such as access to the deeper skin layers [204] or better delivery of ellagic acid through human epidermis and dermis [208].

\section{Summary, Future Perspectives, and Conclusions}

Ellagic acid is present in different medicinal plants and vegetables, as well as in edible fruits and seeds. It can be present as complex polymers called ellagitaninns or in free form, which is hydrolyzed in the digestive tract to give higher plasmatic levels of ellagic acid after its digestion. A great number of authors have described this phenolic acid's various effects, many of which are known from folk medicine and the use of medicinal plants. Ellagic acid's antioxidant properties, for example, are of great interest as they are implicated in most of its pharmacological properties, including anti-inflammatory activities, neuroprotection, hepatoprotection, and protection against diabetes, cardiovascular disease, and cancer. However, other mechanisms are also relevant.

The acid's antioxidant capacity has been attributed to its free radical scavenging activity, which is due to the presence of four hydroxyl and two lactone functional groups that enable ellagic acid to scavenge an extensive variety of ROS, such as hydroxyl, hydroperoxyl, and peroxyl radicals, as well as nitrogen dioxide and peroxynitrite. Thus, ellagic acid has a protective effect against free radical-induced damage, such as gastric lesions, hepatic injury, and hyperlipemia. In addition, the inhibition of lipid peroxidation through the scavenging of hydroxyl and peroxyl radicals can protect various vital organs including the liver, lungs, and brain from oxidative injury. Ellagic acid has also been shown to inhibit the pro-oxidative action of metals such as nickel and ferrous ion through a chelation process and can decrease oxidative DNA 
damage. Moreover, ellagic acid can protect against oxidative injury through the expression of Nrf2 and $\mathrm{HO}-1$.

Because inflammation and oxidative stress are closely linked, the antioxidative effect of ellagic acid is relevant for its anti-inflammatory properties. However, other mechanisms collaborate in the reduction of inflammation, such as the reduction of pro-inflammatory cytokines (IL-1 $\beta$, IL-6, TNF- $\alpha$ ), the increase of anti-inflammatory cytokines (IL-10), and the inhibition of transcription factors (AP-1) and various kinases (MAPK, ERK1/2, JNK). A reduction of the expression of proteins such as VCAM-1 and E-selectin on the surface of endothelial cells was also reported while ICAM-1 did not seem to be affected. Secretion of pro-inflammatory mediators such as MIF and MCP- 1 was also reported, as well as the reduction of TLR2 and TLR4 protein levels and mRNA expression in liver tissues. These data are probably the most relevant as they had not previously been reported. They indicate that the compound could be of high interest against inflammatory diseases associated with TLR signaling.

In the case of metabolic syndrome, inflammation, together with heart disease, diabetes, and stroke, are clear negative factors, as are abdominal obesity, high triglyceride and HDL-cholesterol levels, high blood pressure, and a high fasting blood glucose. The effect of ellagic acid on inflammation have been described above, but its antihypertensive, antihyperglycemic, and antihyperlipidemic properties are also of great interest. There have thus been reports, in the first case, of the acid's ability to inhibit angiotensin I-converting enzyme. In the second case, researchers have described its inhibitory effects on $\alpha$-amylase, $\mathrm{HbA} 1 \mathrm{c}$, hexokinase, glucose-6-phosphatase, and fructose-1,6-bisphosphatase activities, as well as its ability to reduce glycogen and increase insulin. Independent of the effects of glucose metabolism, ellagic acid can reduce the collateral negative effects of hyperglycemia due to sorbitol accumulation and formation of AGEs, thus preventing them from contributing to the complications of type 2 diabetes mellitus, such as cataracts. Ellagic acid also suppresses resistin secretion by a novel mechanism involving the degradation of intracellular resistin protein in adipocytes, a link between obesity and type 2 diabetes mellitus. As for its effects on hyperlipidemia, ellagic acid reduces the oxidation of LDL-cholesterol, oxidized-LDL uptake, and cholesterol influx, all while suppressing foam cell formation. In addition, ellagic acid acts as a PPARy modulator and transfers effluxed cholesterol onto lipid-poor apolipoproteins, initiating the formation of HDL particles and, in consequence, blocking foam cell formation.

Ellagic acid also acts as a potential neuroprotective agent in experimental models of both Alzheimer's and Parkinson's diseases. Indeed, it has positive effects on pro-oxidant and anti-inflammatory mediators, decreases lipid peroxidation, and acts as an ROS scavenger. In addition, ellagic acid has been shown to increase neuronal and memory functions and decrease the amount of brain area lost. Treatment with this phenolic compound downregulates the expression of IL-17 and upregulates the expression of IL-11, decreases the number and proliferation of activated microglia cells, and as a result reduces microglial pro-inflammatory chemokine concentration and moderates brain damage in neuro-inflammatory processes. Ellagic acid also has protective effects against the neural damage caused by Parkinson's disease and has been shown to improve motor impairments and electrophysiological performance in animals. These effects can all be explained by the reduction of the neuro-inflammatory biomarkers TNF- $\alpha$ and $\mathrm{IL}-1 \beta$ as well as the protection of the brain against free radicals, the reduction of MAO-B, and the increase of Nrf2 and HO-1 at the striatal level. These findings indicate that ellagic acid has potential for memory restoration in the treatment of dementia and other cognitive alterations observed in the elderly.

The hepatoprotective effects of ellagic acid are principally due to its free radical scavenging and its regulation of cytokine production, phase I and II catalyzed enzyme reactions, and lipid synthesis and degradation processes. By means of similar mechanisms and other specific pathways, ellagic acid exerts positive effects against various human cancers, including prostate, colon, pancreatic, breast, ovarian, and bladder cancer, as well as glioblastoma and lymphoma. It induces apoptosis, blocks DNA damage generated by oxidative stress and carcinogens, and interferes with inflammation, angiogenesis, and other processes required for tumor progression and metastasis. With regard to its chemopreventive potential, both ellagic acid and its metabolites (principally urolithin A) are of great interest because they have antiproliferative effects, modulate cell cycle regulatory proteins, decrease cyclin B1 and D1 expression, induce cdk-1 phosphorylation, and arrest the cell cycle in $S$ and $\mathrm{G}_{2} / \mathrm{M}$ phases. These compounds have also been shown to exhibit pro-apoptotic activity via a caspasedependent pathway. Ellagic acid has also been shown to downregulate the expression of p-STAT3, p-Akt, and pERK1/2, which could be considered a relevant mechanism for its antiproliferative effects. In addition, it reduced cyclin D1 expression and inactivated the PI3K/Akt pathway, upregulated the expression of Bax, caspase- 3 , and cytochrome $C$, and suppressed $\mathrm{Bcl}-2$.

The principal problem of ellagic acid is its poor solubility in water, which has a relevant effect on its pharmacokinetic properties. Various researchers have described an open two-compartment system with poor absorption and rapid elimination. For this reason, various systems and formulations have been created to improve its bioavailability. These include an ellagic acid-phospholipid complex, a nanomedicine (thermosensitive liposomes), polymer-based nanoparticles, and nano-sized metalla-cages. In the case of skin protection, the use of nanoemulsions has been proposed. However, the relatively low number of clinical studies, with varied protocols and an extremely low number of study subjects, poses a problem for establishing the real potential of this phenolic compound as a possible medicinal agent. However, the experimental data to date, along with the limited results observed in human clinical trials, has piqued a great amount of interest in this metabolite, both as a therapeutic drug and as a component of medicinal plants/food extracts.

\section{Financial Supports}

None.

\section{Conflict of Interest}

The authors declare no conflict of interest. 


\section{References}

[1] PubChem, National Center for Biotechnology Information, U.S. National Library of Medicine. Ellagic acid. 8600 Rockville Pike, Bethesda, MD20894, USA. Available at https://pubchem.ncbi.nlm.nih.gov/ compound/ellagic_acid. Accessed December 14, 2017

[2] Rossi M, Erlebacher ], Zacharias DE, Carrell HL, lannucci B. The crystal and molecular structure of ellagic acid dihydrate: a dietary anti-cancer agent. Carcinogenesis 1991; 12: 2227-2232

[3] Clifford MN, Scalbert A. Ellagitannins-nature, occurrence and dietary burden. J Sci Food Agric 2000; 80: 1118-1125

[4] The National Toxicology Program (NTP). Ellagic acid. Chemical properties. 1992. Available at https://tools.niehs.nih.gov/cebs3/ntpviews/index. cfm?action=testarticle.properties\&cas_number=476-66-4. Accessed December 14, 2017

[5] CAMEO. Ellagic acid. Chemical Datasheet. CAMEO, Chemicals version 2.7 rev 1. Available at https://cameochemicals.noaa.gov/chemical/20329. Accessed December 14, 2017

[6] Derosa G, Maffioli P, Sahebkar A. Ellagic acid and its role in chronic diseases. Adv Exp Med Biol 2016; 928: 473-479

[7] Landete JM. Ellagitannins, ellagic acid and their derived metabolites: a review about source, metabolism, functions and health. Food Res Int 2011. 44: $1150-1160$

[8] Larrosa M, García-Conesa MT, Espín JC, Tomás-Barberán FA. Ellagitannins, ellagic acid and vascular health. Mol Aspects Med 2010; 31: 513-539

[9] Siraj MA, Shilpi JA, Hossain MG, Uddin SJ, Islam MK, Jahan IA, Hossain H. Anti-inflammatory and antioxidant activity of Acalypha hispida leaf and analysis of its major bioactive polyphenols by HPLC. Adv Pharm Bull 2016; 6: 275-283

[10] Aoyama H, Sakagami H, Hatano T. Three new flavonoids, proanthocyanidin, and accompanying phenolic constituents from Feijoa sellowiana. Biosci Biotechnol Biochem 2018; 82: 31-41

[11] Jaramillo-García V, Trindade C, Lima E, Guecheva TN, Villela I, MartinezLopez W, Corrêa DS, Ferraz ABF, Moura S, Sosa MQ, Da Silva J, Henriques JAP. Chemical characterization and cytotoxic, genotoxic, and mutagenic properties of Baccharis trinervis (Lam, Persoon) from Colombia and Brazil. J Ethnopharmacol 2018; 213: 210-220

[12] Yang R, Guan Y, Zhou J, Sun B, Wang Z, Chen H, He Z, Jia A. Phytochemicals from Camellia nitidissima Chi flowers reduce the pyocyanin production and motility of Pseudomonas aeruginosa PAO1. Front Microbiol 2018; 8: 2640

[13] Campos JF, Espindola PPT, Torquato HFV, Vital WD, Justo GZ, Silva DB, Carollo CA, de Picoli Souza K, Paredes-Gamero EJ, Dos Santos EL. Leaf and root extracts from Campomanesia adamantium (Myrtaceae) promote apoptotic death of leukemic cells via activation of intracellular calcium and caspase-3. Front Pharmacol 2017; 8: 466

[14] Yang LP, Gu XL, Chen JX, Yang J, Tan SY, Duan WJ. Chemical constituents from Canarium album Raeusch and their anti-influenza A virus activities. J Nat Med 2018; 72: 808-815

[15] Hafsa J, Hammi KM, Khedher MRB, Smach MA, Charfeddine B, Limem K, Majdoub $\mathrm{H}$. Inhibition of protein glycation, antioxidant and antiproliferative activities of Carpobrotus edulis extracts. Biomed Pharmacother 2016; 84: 1496-1503

[16] Tuyen PT, Xuan TD, Tu Anh TT, Mai Van T, Ahmad A, Elzaawely AA, Khanh TD. Weed suppressing potential and isolation of potent plant growth inhibitors from Castanea crenata Sieb. et Zucc. Molecules 2018; 23: E345

[17] Karimi E, Ghorbani Nohooji M, Habibi M, Ebrahimi M, Mehrafarin A, Khalighi-Sigaroodi F. Antioxidant potential assessment of phenolic and flavonoid rich fractions of Clematis orientalis and Clematis ispahanica (Ranunculaceae). Nat Prod Res 2017. doi:10.1080/14786419. 2017.1359171

[18] Shendge AK, Basu T, Chaudhuri D, Panja S, Mandal N. In vitro antioxidant and antiproliferative activities of various solvent fractions from Clerodendrum viscosum leaves. Pharmacogn Mag 2017; 13 (Suppl. 2): S344-S353
[19] Huang J, Zhang Y, Dong L, Gao Q, Yin L, Quan H, Chen R, Fu X, Lin D. Ethnopharmacology, phytochemistry, and pharmacology of Cornus officinalis Sieb. et Zucc. J Ethnopharmacol 2018; 213: 280-301

[20] Cho CH, Jang H, Lee M, Kang H, Heo H], Kim DO. Sea buckthorn (Hippophae rhamnoides $\mathrm{L}$.) leaf extracts protect neuronal $\mathrm{PC}-12$ cells from oxidative stress. J Microbiol Biotechnol 2017; 27: 1257-1265

[21] Vieira GS, Marques ASF, Machado MTC, Silva VM, Hubinger MD. Determination of anthocyanins and non-anthocyanin polyphenols by ultra performance liquid chromatography/electrospray ionization mass spectrometry (UPLC/ESI-MS) in jussara (Euterpe edulis) extracts. J Food Sci Technol 2017; 54: 2135-2144

[22] Falcão TR, de Araújo AA, Soares LAL, de Moraes Ramos RT, Bezerra ICF, Ferreira MRA, de Souza Neto MA, Melo MCN, de Araújo RF jr., de Aguiar Guerra ACV, de Medeiros JS, Guerra GCB. Crude extract and fractions from Eugenia uniflora Linn leaves showed anti-inflammatory, antioxidant, and antibacterial activities. BMC Complement Altern Med 2018; 18: 84

[23] Lee IS, Jung SH, Kim JS. Polyphenols from Euphorbia pekinensis inhibit AGEs formation in vitro and vessel dilation in larval zebrafish in vivo. Planta Med 2018; 84: 176-181

[24] Ton That Q, Nguyen Thien TV, Dang HP, Le Hoan N, Vo LKT, Nguyen MHD, Ngu NT, Nguyen TS, Hansen PE. Chemical constituents of Geum urbanum L. roots. Nat Prod Res 2018. doi:10.1080/14786419. 2018.1425844

[25] Ochoa-Pacheco A, Escalona Arranz JC, Beaven M, Peres-Roses R, Gámez YM, Camacho-Pozo MI, Maury GL, de Macedo MB, Cos P, Tavares JF, Da Silva MS. Bioassay-guided in vitro study of the antimicrobial and cytotoxic properties of the leaves from Excoecaria lucida Sw. Pharmacognosy Res 2017; 9: 396-400

[26] Vu D, Vo P, Coggeshall M, Lin CH. Identification and characterization of phenolic compounds in black walnut kernels. J Agric Food Chem 2018; 66: 4503-4511

[27] Pereira LOM, Vilegas W, Tangerina MMP, Arunachalam K, Balogun SO, Orlandi-Mattos PE, Colodel EM, Martins DTO. Lafoensia pacari A. St.-Hil.: wound healing activity and mechanism of action of standardized hydroethanolic leaves extract. J Ethnopharmacol 2018; 219: 337-350

[28] de Oliveira LM, Porte A, de Oliveira Godoy RL, da Costa Souza M, Pacheco S, de Araujo Santiago MCP, Gouvêa ACMS, da Silva de Mattos do Nascimento L, Borguini RG. Chemical characterization of Myrciaria floribunda (H. West ex Willd) fruit. Food Chem 2018; 248: 247-252

[29] Díaz-de-Cerio E, Arráez-Román D, Segura-Carretero A, Ferranti $P$, Nicoletti R, Perrotta GM, Gómez-Caravaca AM. Establishment of pressurized-liquid extraction by response surface methodology approach coupled to HPLC-DAD-TOF-MS for the determination of phenolic compounds of myrtle leaves. Anal Bioanal Chem 2018; 410: 3547-3557

[30] Hernández C, Ascacio-Valdés ], De la Garza H, Wong-Paz J, Aguilar CN, Martínez-Ávila GC, Castro-López C, Aguilera-Carbó A. Polyphenolic content, in vitro antioxidant activity and chemical composition of extract from Nephelium lappaceum L. (Mexican rambutan) husk. Asian Pac J Trop Med 2017; 10: 1201-1205

[31] Ifeanacho MO, Ikewuchi CC, Ikewuchi JC. Investigation of the profile of phenolic compounds in the leaves and stems of Pandiaka heudelotii using gas chromatography coupled with flame ionization detector. Food Sci Nutr 2016; 5: 646-652

[32] Navarro M, Moreira I, Arnaez E, Quesada S, Azofeifa G, Vargas F, Alvarado D, Chen P. Flavonoids and ellagitannins characterization, antioxidant and cytotoxic activities of Phyllanthus acuminatus Vahl. Plants (Basel) 2017; 6: E62

[33] Hu Q, Yuan B, Xiao H, Zhao L, Wu X, Rakariyatham K, Zhong L, Han Y, Muinde Kimatu B, Yang W. Polyphenols-rich extract from Pleurotus eryngii with growth inhibitory of HCT116 colon cancer cells and anti-inflammatory function in RAW264.7 cells. Food Funct 2018; 9: 1601-1611

[34] Inada KOP, Duarte PA, Lapa J, Miguel MAL, Monteiro M. Jabuticaba (Myrciaria jaboticaba) juice obtained by steam-extraction: phenolic compound profile, antioxidant capacity, microbiological stability, and sensory acceptability. J Food Sci Technol 2018; 55: 52-61 
[35] Neves NA, Stringheta PC, Gómez-Alonso S, Hermosín-Gutiérrez I. Flavonols and ellagic acid derivatives in peels of different species of jabuticaba (Plinia spp.) identified by HPLC-DAD-ESI/MSn. Food Chem 2018; 252: 6171

[36] Mazzarino L, da Silva Pitz H, Lorenzen Voytena AP, Dias Trevisan AC, Ribeiro-Do-Valle RM, Maraschin M. Jaboticaba (Plinia peruviana) extract nanoemulsions: development, stability, and in vitro antioxidant activity. Drug Dev Ind Pharm 2018; 44: 643-651

[37] Morikawa T, Imura K, Akagi Y, Muraoka O, Ninomiya K. Ellagic acid glycosides with hepatoprotective activity from traditional Tibetan medicine Potentilla anserina. J Nat Med 2018; 72: 317-325

[38] Sobral-Souza CE, Silva ARP, Leite NF, Costa JGM, Menezes IRA, Cunha FAB, Rolim LA, Coutinho HDM. LC-MS analysis and cytoprotective effect against the mercurium and aluminium toxicity by bioactive products of Psidium brownianum Mart. ex DC. J Hazard Mater 2018. doi:10.1016/j. jhazmat.2018.03.039

[39] Odubanjo VO, Ibukun EO, Oboh G, Adefegha SA. Aqueous extracts of two tropical ethnobotanicals (Tetrapleura tetraptera and Quassia undulata) improved spatial and non-spatial working memories in scopolamine-induced amnesic rats: influence of neuronal cholinergic and antioxidant systems. Biomed Pharmacother 2018; 99: 198-204

[40] Ghadage DM, Kshirsagar PR, Pai SR, Chavan JJ. Extraction efficiency, phytochemical profiles and antioxidative properties of different parts of Saptarangi (Salacia chinensis L.) - an important underutilized plant. Biochem Biophys Rep 2017; 12: 79-90

[41] Pinto J, Spínola V, Llorent-Martínez EJ, Fernández-de Córdova ML, MolinaGarcía L, Castilho PC. Polyphenolic profile and antioxidant activities of Madeiran elderberry (Sambucus lanceolata) as affected by simulated in vitro digestion. Food Res Int 2017; 100: 404-410

[42] Im SH, Wang Z, Lim SS, Lee OH, Kang IJ. Bioactivity-guided isolation and identification of anti-adipogenic compounds from Sanguisorba officinalis. Pharm Biol 2017; 55: 2057-2064

[43] Cui Q, Du R, Anantpadma M, Schafer A, Hou L, Tian J, Davey RA, Cheng H, Rong L. Identification of ellagic acid from plant Rhodiola rosea $\mathrm{L}$. as an anti-Ebola virus entry inhibitor. Viruses 2018; 10: E152

[44] de Britto Policarpi P, Turcatto L, Demoliner F, Ferrari RA, Bascuñan VLAF, Ramos JC, Jachmanián I, Vitali L, Micke GA, Block JM. Nutritional potential, chemical profile and antioxidant activity of Chichá (Sterculia striata) nuts and its by-products. Food Res Int 2018; 106: 736-744

[45] Sathyanarayanan S, Chandran R, Thankarajan S, Abrahamse H, Thangaraj P. Phytochemical composition, antioxidant and anti-bacterial activity of Syzygium calophyllifolium Walp. fruit. J Food Sci Technol 2018; 55: 341350

[46] Gajera HP, Gevariya SN, Hirpara DG, Patel SV, Golakiya BA. Antidiabetic and antioxidant functionality associated with phenolic constituents from fruit parts of indigenous black jamun (Syzygium cumini L.) landraces. J Food Sci Technol 2017; 54: 3180-3191

[47] Kalra P, Karwasra R, Gupta YK, Ray SB, Singh S. Terminalia chebula supplementation attenuates cisplatin-induced nephrotoxicity in Wistar rats through modulation of apoptotic pathway. Nat Prod Res 2018. doi:10.1080/14786419.2018.1425843

[48] Cesário FRAS, de Albuquerque TR, de Lacerda GM, de Oliveira MRC, Rodrigues LB, Martins AOBPB, Boligon AA, Júnior LJQ, de Souza Araújo AA, Vale ML, Coutinho HDM, de Menezes IRA. Phytochemical profile and mechanisms involved in the anti-nociception caused by the hydroethanolic extract obtained from Tocoyena formosa (Cham. \& Schltdl.) K. Schum (Jenipapo-bravo) leaves in mice. Biomed Pharmacother 2018; 97 : 321-329

[49] Sabir SM, Rocha JBT, Boligon AA, Athayde ML. Hepatoprotective activity and phenolic profile of Zanthoxylum alatum Roxb. fruit extract. Pak J Pharm Sci 2017; 30: 1551-1556

[50] García-Niño W, Zazueta C. Ellagic acid: pharmacological activities and molecular mechanisms involved in liver protection. Pharmacol Res 2015; 97: 84-103
[51] de Oliveira MR. The effects of ellagic acid upon brain cells: a mechanistic view and future directions. Neurochem Res 2016; 41: 1219-1228

[52] Ratnam DV, Ankola DD, Bhardwaj V, Sahana DK, Kumar MN. Role of antioxidants in prophylaxis and therapy: a pharmaceutical perspective. J Control Release 2006; 113: 189-207

[53] Salem AM, Mohammaden TF, Mohamed MAM, Mohamed EA, Hasan HF. Ellagic and ferulic acids alleviate gamma radiation and aluminium chloride-induced oxidative damage. Life Sci 2016; 160: 2-11

[54] Priyadarsini KI, Khopde SM, Kumar SS, Mohan H. Free radical studies of ellagic acid, a natural phenolic antioxidant. J Agric Food Chem 2002; 50: 2200-2206

[55] Galano A, Francisco-Márquez M, Pérez-González A. Ellagic acid: an unusually versatile protector against oxidative stress. Chem Res Toxicol 2014; 27: 904-918

[56] Tiwari MK, Mishra PC. Modeling the scavenging activity of ellagic acid and its methyl derivatives towards hydroxyl, methoxy, and nitrogen dioxide radicals. J Mol Model 2013; 19: 5445-5456

[57] Marković Z, Milenković D, Đorović ], Marković JMD, Lučić B, Amić D. A DFT and PM6 study of free radical scavenging activity of ellagic acid. Monatsh Chem 2013; 144: 803-812

[58] Ahmed T, Setzer WN, Nabavi SF, Orhan IE, Braidy N, Sobarzo-Sanchez E, Nabavi SM. Insights into effects of ellagic acid on the nervous system: a mini review. Curr Pharm Des 2016; 22: 1350-1360

[59] lino T, Nakahara K, Miki W, Kiso Y, Ogawa Y, Kato S, Takeuchi K. Less damaging effect of whisky in rat stomachs in comparison with pure ethanol. Role of ellagic acid, the nonalcoholic component. Digestion 2001; 64: 214-221

[60] lino T, Tashima K, Umeda M, Ogawa Y, Takeeda M, Takata K. Takeuchi K. Effect of ellagic acid on gastric damage induced in ischemic rat stomachs following ammonia or reperfusion. Life Sci 2002; 70: 1139-1150

[61] Hassoun EA, Walter AC, Alsharif NZ, Stohs SJ. Modulation of TCDD-induced fetotoxicity and oxidative stress in embryonic and placental tissues of C57BL/6] mice by vitamin E succinate and ellagic acid. Toxicology 1997; 124: $27-37$

[62] Yu YM, Chang WC, Wu CH, Chiang SY. Reduction of oxidative stress and apoptosis in hyperlipidemic rabbits by ellagic acid. J Nutr Biochem 2005; 16: 675-681

[63] Böyük A, Önder A, Kapan M, Gümüş M, Firat U, Başarali MK, Alp H. Ellagic acid ameliorates lung injury after intestinal ischemia-reperfusion. Pharmacogn Mag 2011; 7: 224-228

[64] Uzar E, Alp H, Cevik MU, Fırat U, Evliyaoglu O, Tufek A, Altun Y. Ellagic acid attenuates oxidative stress on brain and sciatic nerve and improves histopathology of brain in streptozotocin-induced diabetic rats. Neurol Sci 2012; 33: 567-574

[65] Kilic I, Yeșiloğlu Y, Bayrak Y. Spectroscopic studies on the antioxidant activity of ellagic acid. Spectrochim Acta A Mol Biomol Spectrosc 2014; 130: 447-452

[66] Roche A, Ross E, Walsh N, O’Donnell K, Williams A, Klapp M, Fullard N, Edelstein S. Representative literature on the phytonutrients category: phenolic acids. Crit Rev Food Sci Nutr 2015; 57: 1089-1096

[67] Hassoun EA, Vodhanel ], Abushaban A. The modulatory effects of ellagic acid and vitamin E succinate on TCDD-induced oxidative stress in different brain regions of rats after subchronic exposure. J Biochem Mol Toxicol 2004; 18: 196-203

[68] Lee W], Ou HC, Hsu WC, Chou MM, Tseng J], Hsu SL, Tsai KL, Sheu WH. Ellagic acid inhibits oxidized LDL-mediated LOX-1 expression, ROS generation, and inflammation in human endothelial cells. J Vasc Surg 2010; 52: 1290-1300

[69] Berkban T, Boonprom P, Bunbupha S, Welbat JU, Kukongviriyapan U, Kukongviriyapan V, Pakdeechote P, Prachaney P. Ellagic acid prevents LNAME-induced hypertension via restoration of eNOS and $p 47^{\text {phox }}$ expression in rats. Nutrients 2015; 7: 5265-5280 
[70] Mira L, Fernandez MT, Santos M, Rocha R, Florêncio MH, Jennings KR. Interactions of flavonoids with iron and copper ions: a mechanism for their antioxidant activity. Free Radic Res 2002; 36: 1199-1208

[71] Craft BD, Kerrihard AL, Amarowicz R, Pegg RB. Phenol-based antioxidants and the in vitro methods used for their assessment. Compr Rev Food Sci Food Saf 2012; 11: 148-173

[72] Ahmed S, Rahman A, Saleem M, Athar M, Sultana S. Ellagic acid ameliorates nickel induced biochemical alterations: diminution of oxidative stress. Hum Exp Toxicol 1999; 18: 691-698

[73] Yang CS, Tzou BC, Liu YP, Tsai M], Shyue SK, Tzeng SF. Inhibition of cadmium-induced oxidative injury in rat primary astrocytes by the addition of antioxidants and the reduction of intracellular calcium. J Cell Biochem 2008; 103: 825-834

[74] Saha P, Yeoh BS, Singh R, Chandrasekar B, Vemula PK, Haribabu B, VijayKumar M, Jala VR. Gut microbiota conversion of dietary ellagic acid into bioactive phytoceutical urolithin A inhibits heme peroxidases. PLoS One 2016; 11: e0156811

[75] Dalvi LT, Moreira DC, Andrade R jr., Ginani ], Alonso A, Hermes-Lima M. Ellagic acid inhibits iron-mediated free radical formation. Spectrochim Acta A Mol Biomol Spectrosc 2017; 173: 910-917

[76] Srinivasan P, Vadhanam MV, Arif JM, Gupta RC. A rapid screening assay for antioxidant potential of natural and synthetic agents in vitro. Int J Oncol 2002; 20: 983-986

[77] Sai-Kato K, Umemura T, Takagi A, Hasegawa R, Tanimura A, Kurokawa Y. Pentachlorophenol-induced oxidative DNA damage in mouse liver and protective effect of antioxidants. Food Chem Toxicol 1995; 33: 877-882

[78] Teel RW, Martin RM, Allahyari R. Ellagic acid metabolism and binding to DNA in organ explant cultures of the rat. Cancer Lett 1987; 36: 203-211

[79] Thulstrup PW, Thormann T, Spanget-Larsen J, Bisgaard HC. Interaction between ellagic acid and calf thymus DNA studied with flow linear dichroism UV-VIS spectroscopy. Biochem Biophys Res Commun 1999; 265: 416-421

[80] Spencer WA, Jeyabalan J, Kichambre S, Gupta RC. Oxidatively generated DNA damage after $\mathrm{Cu}(\mathrm{II})$ catalysis of dopamine and related catecholamine neurotransmitters and neurotoxins: role of reactive oxygen species. Free Radic Biol Med 2011; 50: 139-147

[81] Li W, Kong AN. Molecular mechanisms of Nrf2-mediated antioxidant response. Mol Carcinog 2009; 48: 91-104

[82] Baek B, Lee SH, Kim K, Lim HW, Lim C]. Ellagic acid plays a protective role against UV-B-induced oxidative stress by up-regulating antioxidant components in human dermal fibroblasts. Korean J Physiol Pharmacol 2016; 20: 269-277

[83] Hseu YC, Chou CW, Senthil Kumar KJ, Fu KT, Wang HM, Hsu LS, Kuo YH, Wu CR, Chen SC, Yang HL. Ellagic acid protects human keratinocyte ( $\mathrm{HaCaT}$ ) cells against UVA-induced oxidative stress and apoptosis through the upregulation of the $\mathrm{HO}-1$ and $\mathrm{Nrf}-2$ antioxidant genes. Food Chem Toxicol 2012; 50: 1245-1255

[84] Gu L, Deng WS, Liu Y, Jiang CH, Sun LC, Sun XF, Xu Q, Zhou H. Ellagic acid protects lipopolysaccharide/D-galactosamine-induced acute hepatic injury in mice. Int Immunopharmacol 2014; 22: 341-345

[85] Ding Y, Zhang B, Zhou K, Chen M, Wang M, Jia Y, Song Y, Li Y, Wen A. Dietary ellagic acid improves oxidant-induced endothelial dysfunction and atherosclerosis: role of Nrf2 activation. Int J Cardiol 2014; 175: 508-514

[86] Shepherd AG, Manson MM, Ball HWL, McLellan LI. Regulation of rat glutamate-cysteine ligase ( $\gamma$-glutamylcysteine synthetase) subunits by chemopreventive agents and in aflatoxin $\mathrm{B}_{1}$-induced preneoplasia. Carcinogenesis 2000; 21: 1827-1834

[87] Hayes JD, McLellan LI. Glutathione and glutathione-dependent enzymes represent a co-ordinately regulated defence against oxidative stress. Free Radic Res 1999; 31: 273-300

[88] Mishra S, Vinayak M. Ellagic acid inhibits PKC signaling by improving antioxidant defense system in murine T cell lymphoma. Mol Biol Rep 2014; 41: 4187-4197
[89] Ding Y, Wang L, Song J, Zhou S. Protective effects of ellagic acid against tetrachloride-induced cirrhosis in mice through the inhibition of reactive oxygen species formation and angiogenesis. Exp Ther Med 2017; 14: 3375-3380

[90] Biswas S. Does the interdependence between oxidative stress and inflammation explain the antioxidant paradox? Oxid Med Cell Longev 2016; 2016: 1-9

[91] Chao C, Mong M, Chan K, Yin M. Anti-glycative and anti-inflammatory effects of caffeic acid and ellagic acid in kidney of diabetic mice. Mol Nutr Food Res 2010; 54: 388-395

[92] Mo J, Panichayupakaranant P, Kaewnopparat N, Songkro S, Reanmongkol W. Topical anti-inflammatory potential of standardized pomegranate rind extract and ellagic acid in contact dermatitis. Phytother Res 2014; 28: 629-632

[93] Yılmaz E, Bozdağ Z, Ibiloğlu I, Arıkanoğlu Z, Yazgan Ü, Kaplan I, Gümüs M, Atamanalp SS. Therapeutic effects of ellagic acid on L-arginin induced acute pancreatitis. Acta Cir Bras 2016; 31: 396-401

[94] Masamune A, Satoh M, Kikuta K, Suzuki N, Satoh K, Shimosegawa T. Ellagic acid blocks activation of pancreatic stellate cells. Biochem Pharmacol 2005; 70: 869-878

[95] González-Sarrías A, Larrosa M, Tomás-Barberán F, Dolara P, Espín J. NF$\kappa \mathrm{B}$-dependent anti-inflammatory activity of urolithins, gut microbiota ellagic acid-derived metabolites, in human colonic fibroblasts. $\mathrm{Br}$ ] Nutr 2010; 104: 503-512

[96] Cornélio Favarin D, Martins Teixeira M, Lemos de Andrade E, de Freitas Alves C, Lazo Chica JE, Artério Sorgi C, Faccioli LH, Paula Rogerio A. Antiinflammatory effects of ellagic acid on acute lung injury induced by acid in mice. Mediators Inflamm 2013; 2013: 1-13

[97] Marín M, Giner RM, Ríos JL, Recio MC. Intestinal anti-inflammatory activity of ellagic acid in the acute and chronic dextrane sulfate sodium models of mice colitis. J Ethnopharmacol 2013; 150: 925-934

[98] Romier B, Van De Walle J, During A, Larondelle Y, Schneider Y. Modulation of signalling nuclear factor- $\kappa \mathrm{B}$ activation pathway by polyphenols in human intestinal Caco-2 cells. Br J Nutr 2008; 100: 542-551

[99] Rosillo M, Sánchez-Hidalgo M, Cárdeno A, Aparicio-Soto M, Sánchez-Fidalgo S, Villegas I, de la Lastra CA. Dietary supplementation of an ellagic acid-enriched pomegranate extract attenuates chronic colonic inflammation in rats. Pharmacol Res 2012; 66: 235-242

[100] Allahverdi T, Allahverdi E, Yayla S, Deprem T, Merhan O, Vural S. The comparison of the effects of ellagic acid and diclofenac sodium on intra-abdominal adhesion: an in vivo study in the rat model. Int Surg 2014; 99: 543-550

[101] Zhou E, Fu Y, Wei Z, Yang Z. Inhibition of allergic airway inflammation through the blockage of NF- $k \mathrm{~B}$ activation by ellagic acid in an ovalbumin-induced mouse asthma model. Food Funct 2014; 5: 2106-2112

[102] Ghasemi-Niri S, Maqbool F, Baeeri M, Gholami M, Abdollahi M. Phosalone-induced inflammation and oxidative stress in the colon: evaluation and treatment. World ] Gastroenterol 2016; 22: 4999

[103] Chun K. Nitric oxide induces expression of cyclooxygenase-2 in mouse skin through activation of NF- $K B$. Carcinogenesis 2003; 25: 445-454

[104] El-Shitany N, El-Bastawissy E, El-desoky K. Ellagic acid protects against carrageenan-induced acute inflammation through inhibition of nuclear factor kappa B, inducible cyclooxygenase and proinflammatory cytokines and enhancement of interleukin-10 via an antioxidant mechanism. Int Immunopharmacol 2014; 19: 290-299

[105] Karlsson S, Nånberg E, Fjaeraa C, Wijkander ]. Ellagic acid inhibits lipopolysaccharide-induced expression of enzymes involved in the synthesis of prostaglandin $E_{2}$ in human monocytes. Br J Nutr 2010; 103: $1102-$ 1109

[106] Chang WC, Yu YM, Chiang SY, Tseng CY. Ellagic acid suppresses oxidised low-density lipoprotein-induced aortic smooth muscle cell proliferation: studies on the activation of extracellular signal-regulated kinase $1 / 2$ and proliferating cell nuclear antigen expression. Br J Nutr 2008; 99: 709-714 
[107] Hwang D, Jang BC, Yu G, Boudreau M. Expression of mitogen-inducible cyclooxygenase induced by lipopolysaccharide: mediation through both mitogen-activated protein kinase and NF- $k B$ signaling pathways in macrophages. Biochem Pharmacol 1997; 54: 87-96

[108] Scherle PA, Ma W, Lim H, Dey SK, Trzaskos JM. Regulation of cyclooxygenase- 2 induction in the mouse uterus during decidualization. An event of early pregnancy. J Biol Chem 2000; 275: 37086-37092

[109] Arbabi S, Rosengart MR, Garcia I, Maier RV. Hypertonic saline solution induces prostacyclin production by increasing cyclooxygenase-2 expression. Surgery 2000; 128: 198-205

[110] Masuko-Hongo K, Berenbaum F, Humbert L, Salvat C, Goldring MB, Thirion S. Up-regulation of microsomal prostaglandin $E$ synthase 1 in osteoarthritic human cartilage: critical roles of the ERK-1/2 and p38 signaling pathways. Arthritis Rheum 2004; 50: 2829-2838

[111] Umesalma S, Sudhandiran G. Differential inhibitory effects of the polyphenol ellagic acid on inflammatory mediators NF- $\mathrm{B}$, iNOS, COX-2, TNF- $\alpha$ and IL-6 in 1, 2-dimethylhydrazine-induced rat colon carcinogenesis. Basic Clin Pharmacol Toxicol 2010; 107: 650-655

[112] Mansouri MT, Hemmati AA, Naghizadeh B, Mard SA, Rezaie A, Ghorbanzadeh B. A study of the mechanisms underlying the anti-inflammatory effect of ellagic acid in carrageenan-induced paw edema in rats. Indian J Pharmacol 2015; 47: 292-298

[113] Papoutsi Z, Kassi E, Chinou I, Halabalaki M, Skaltsounis L, Moutsatsou P. Walnut extract (Juglans regia L.) and its component ellagic acid exhibit anti-inflammatory activity in human aorta endothelial cells and osteoblastic activity in the cell line KS483. Br J Nutr 2007; 99: 715-722

[114] Yu Y, Wang Z, Liu C, Chen C. Ellagic acid inhibits IL- $1 \beta$-induced cell adhesion molecule expression in human umbilical vein endothelial cells. $\mathrm{Br}$ J Nutr 2007; 97: 692-698

[115] Alves CdF, Angeli G, Favarin D, de Andrade EL, Lazo Chica J, Faccioli L, da Silva PR, Rogerio AdP. The effects of proresolution of ellagic acid in an experimental model of allergic airway inflammation. Mediators Inflamm 2013; 2013: 1-9

[116] Sarkar S, Siddiqui A, Mazumder S, De R, Saha S, Banerjee C, Iqbal MS, Adhikari S, Alam A, Roy S, Bandyopadhyay U. Ellagic acid, a dietary polyphenol, inhibits tautomerase activity of human macrophage migration inhibitory factor and its pro-inflammatory responses in human peripheral blood mononuclear cells. J Agric Food Chem 2015; 63: 4988-4998

[117] Seo CS, Jeong SJ, Yoo SR, Lee NR, Shin HK. Quantitative analysis and in vitro anti-inflammatory effects of gallic acid, ellagic acid, and quercetin from Radix Sanguisorbae. Pharmacogn Mag 2016; 12: 104-108

[118] Anderson K, Teuber S. Ellagic acid and polyphenolics present in walnut kernels inhibit in vitro human peripheral blood mononuclear cell proliferation and alter cytokine production. Ann N Y Acad Sci 2010; 1190: 86-96

[119] Bae JY, Choi JS, Kang SW, Lee Y], Park J, Kang YH. Dietary compound ellagic acid alleviates skin wrinkle and inflammation induced by UV-B irradiation. Exp Dermatol 2010; 19: e182-e190

[120] Chatterjee A, Chatterjee S, Das S, Saha A, Chattopadhyay S, Bandyopadhyay S. Ellagic acid facilitates indomethacin-induced gastric ulcer healing via COX-2 up-regulation. Acta Biochim Biophys Sin (Shanghai) 2012; 44: 565-576

[121] Allam G, Mahdi E, Alzahrani A, Abuelsaad A. Ellagic acid alleviates adjuvant induced arthritis by modulation of pro- and anti-inflammatory cytokines. Cent Eur J Immunol 2016; 4: 339-349

[122] Ahad A, Ganai A, Mujeeb M, Siddiqui W. Ellagic acid, an NF-kB inhibitor, ameliorates renal function in experimental diabetic nephropathy. Chem Biol Interact 2014; 219: 64-75

[123] Aggarwal S, Ghilardi N, Xie MH, De Sauvage FJ, Gurney AL. Interleukin23 promotes a distinct CD4 T cell activation state characterized by the production of interleukin-17. J Biol Chem 2003; 278: 1910-1914

[124] Moseley TA, Haudenschild DR, Rose L, Reddi AH. Interleukin-17 family and IL-17 receptors. Cytokine Growth Factor Rev 2003; 14: 155-174
[125] Sanadgol N, Golab F, Tashakkor Z, Taki N, Moradi Kouchi S, Mostafaie A Mehdizadeh M, Abdollahi M, Taghizadeh G, Sharifzadeh M. Neuroprotective effects of ellagic acid on cuprizone-induced acute demyelination through limitation of microgliosis, adjustment of CXCL12/IL-17/IL-11 axis and restriction of mature oligodendrocytes apoptosis. Pharm Biol 2017; 55: 1679-1687

[126] Filannino P, Azzi L, Cavoski I, Vincentini O, Rizzello C, Gobbetti M, D Cagno R. Exploitation of the health-promoting and sensory properties of organic pomegranate (Punica granatum L.) juice through lactic acid fermentation. Int J Food Microbiol 2013; 163: 184-192

[127] Lee J, Won J, Choi J, Cha H, Jang Y, Park S, Kim HG, Kim HC, Kim DK. Protective effect of ellagic acid on concanavalin A induced hepatitis via toll-like receptor and mitogen-activated protein kinase/nuclear factor KB signaling pathways. J Agric Food Chem 2014; 62: 10110-10117

[128] National Heart, Lung, and Blood Institute. Metabolic syndrome. Available at https://www.nhlbi.nih.gov/health/health-topics/topics/ms. Accessed January 12, 2018

[129] American Heart Association. What is Metabolic syndrome? Available at https://www.heart.org/idc/groups/heart-public/@wcm/@hcm/ documents/downloadable/ucm_300322.pdf. Accessed January 12 2018

[130] Jurenka JS. Therapeutic applications of pomegranate (Punica granatum L.): a review. Altern Med Rev 2008; 13: 128-144

[131] Johanningsmeier SD, Harris GK. Pomegranate as a functional food and nutraceutical source. Annu Rev Food Sci Technol 2011; 2: 181-201

[132] Banihani S, Swedan S, Alguraan Z. Pomegranate and type 2 diabetes. Nutr Res 2013; 33: 341-348

[133] Pinto Mda S, de Carvalho JE, Lajolo FM, Genovese MI, Shetty K. Evaluation of antiproliferative, anti-type 2 diabetes, and antihypertension potentials of ellagitannins from strawberries (Fragaria $\times$ ananassa Duch.) using in vitro models. J Med Food 2010; 13: 1027-1035

[134] Malini P, Kanchana G, Murugan R. Antidiabetic efficacy of ellagic acid in streptozotocin-induced diabetes mellitus in rats. Asian J Pharm Clin Res 2011; 4: 124-128

[135] Uzor PF, Osadebe PO. Antidiabetic activity of the chemical constituents of Combretum dolichopetalum root in mice. EXCLI ] 2016; 15: 290-296

[136] Amin MM, Arbid MS. Estimation of ellagic acid and/or repaglinide ef fects on insulin signaling, oxidative stress, and inflammatory mediators of liver, pancreas, adipose tissue, and brain in insulin resistant/type $2 \mathrm{di}$ abetic rats. Appl Physiol Nutr Metab 2017; 42: 181-192

[137] Ueda H, Kawanishi K, Moriyasu M. Effects of ellagic acid and 2-(2,3,6trihydroxy-4-carboxyphenyl)ellagic acid on sorbitol accumulation in vitro and in vivo. Biol Pharm Bull 2004; 27: 1584-1587

[138] Panchal SK, Ward L, Brown L. Ellagic acid attenuates high-carbohydrate, high-fat diet-induced metabolic syndrome in rats. Eur J Nutr 2013; 52: 559-568

[139] Ma Q. Role of Nrf2 in oxidative stress and toxicity. Annu Rev Pharmaco Toxicol 2013; 53: 401-426

[140] Jiménez-Osorio AS, González-Reyes S, Pedraza-Chaverri ]. Natural Nrf2 activators in diabetes. Clin Chim Acta 2015; 448: 182-192

[141] Soetikno V, Sari FR, Veeraveedu PT, Thandavarayan RA, Harima M, Sukumaran V, Lakshmanan AP, Suzuki K, Kawachi H, Watanabe K. Curcumin ameliorates macrophage infiltration by inhibiting NF- $\kappa$ B activation and proinflammatory cytokines in streptozotocin induced-diabetic nephropathy. Nutr Metab (Lond) 2011; 8: 35

[142] Kumagai Y, Nakatani S, Onodera H, Nagatomo A, Nishida N, Matsuura Y, Kobata K, Wada M. Anti-glycation effects of pomegranate (Punica granatum L.) fruit extract and its components in vivo and in vitro. J Agric Food Chem 2015; 63: 7760-7764

[143] Rao AR, Veeresham C, Asres K. In vitro and in vivo inhibitory activities of four Indian medicinal plant extracts and their major components on rat aldose reductase and generation of advanced glycation end products. Phytother Res 2013; 27: 753-760 
[144] Ahmed N. Advanced glycation endproducts - role in pathology of diabetic complications. Diabetes Res Clin Pract 2005; 67: 3-21

[145] Peyroux ], Sternberg M. Advanced glycation end products (AGEs): pharmacological inhibition in diabetes. Pathol Biol 2006; 54: 405-419

[146] Aslan HE, Beydemir Ş. Phenolic compounds: the inhibition effect on polyol pathway enzymes. Chem Biol Interact 2017; 266: 47-55

[147] Muthenna P, Akileshwari C, Reddy GB. Ellagic acid, a new antiglycating agent: its inhibition of $\mathrm{N}^{E}$-(carboxymethyl)lysine. Biochem J 2012; 442: 221-230

[148] Raghu G, Jakhotia S, Yadagiri Reddy P, Kumar PA, Bhanuprakash Reddy G. Ellagic acid inhibits non-enzymatic glycation and prevents proteinuria in diabetic rats. Food Funct 2016; 7: 1574-1583

[149] Makino-Wakagi Y, Yoshimura Y, Uzawa Y, Zaima N, Moriyama T, Kawamura $Y$. Ellagic acid in pomegranate suppresses resistin secretion by a novel regulatory mechanism involving the degradation of intracelIular resistin protein in adipocytes. Biochem Biophys Res Commun 2012; 417: 880-885

[150] Yoshimura Y, Nishii S, Zaima N, Moriyama T, Kawamura Y. Ellagic acid improves hepatic steatosis and serum lipid composition through reduction of serum resistin levels and transcriptional activation of hepatic ppara in obese, diabetic KK- $A^{y}$ mice. Biochem Biophys Res Commun 2013; 434: 486-491

[151] Kam A, Li KM, Razmovski-Naumovski V, Nammi S, Shi ], Chan K, Li GQ. A comparative study on the inhibitory effects of different parts and chemical constituents of pomegranate on $\alpha$-amylase and $\alpha$-glucosidase. Phytother Res 2013; 27: 1614-1620

[152] Bellesia A, Verzelloni E, Tagliazucchi D. Pomegranate ellagitannins inhibit $\alpha$-glucosidase activity in vitro and reduce starch digestibility under simulated gastro-intestinal conditions. Int J Food Sci Nutr 2015; 66: 8592

[153] Somsák L, Czifrák K, Tóth M, Bokor E, Chrysina ED, Alexacou KM, Hayes JM, Tiraidis C, Lazoura E, Leonidas DD, Zographos SE, Oikonomakos NG. New inhibitors of glycogen phosphorylase as potential antidiabetic agents. Curr Med Chem 2008; 15: 2933-2983

[154] Kyriakis E, Stravodimos GA, Kantsadi AL, Chatzileontiadou DS, Skamnaki VT, Leonidas DD. Natural flavonoids as antidiabetic agents. The binding of gallic and ellagic acids to glycogen phosphorylase b. FEBS Lett 2015; 589: 1787-1794

[155] Fatima N, Hafizur RM, Hameed A, Ahmed S, Nisar M, Kabir N. Ellagic acid in Emblica officinalis exerts anti-diabetic activity through the action on $\beta$-cells of pancreas. Eur J Nutr 2017; 56: 591-601

[156] Kang I, Buckner T, Shay NF, Gu L, Chung S. Improvements in metabolic health with consumption of ellagic acid and subsequent conversion into urolithins: evidence and mechanisms. Adv Nutr 2016; 7: 961-972

[157] Glass CK, Witztum JL. Atherosclerosis: the road ahead. Cell 2001; 104: 503-516

[158] Park SH, Kim JL, Lee ES, Han SY, Gong JH, Kang MK, Kang YH. Dietary ellagic acid attenuates oxidized LDL uptake and stimulates cholesterol efflux in murine macrophages. J Nutr 2011; 141: 1931-1937

[159] Rigamonti E, Chinetti-Gbaguidi G, Staels B. Regulation of macrophage functions by PPAR- $\alpha$, PPAR- $\gamma$, and LXRs in mice and men. Arterioscler Thromb Vasc Biol 2008; 28: 1050-1059

[160] Rani UP, Kesavan R, Ganugula R, Avaneesh T, Kumar UP, Reddy GB, Dixit M. Ellagic acid inhibits PDGF-BB-induced vascular smooth muscle cell proliferation and prevents atheroma formation in streptozotocin-induced diabetic rats. J Nutr Biochem 2013; 24: 1830-1839

[161] Mansouri MT, Farbood Y, Naghizadeh B, Shabani S, Mirshekar MA, Sarkaki A. Beneficial effects of ellagic acid against animal models of scopolamine- and diazepam-induced cognitive impairments. Pharm Biol 2016; 54: 1947-1953

[162] Bansal N, Yadav P, Kumar M. Ellagic acid administration negated the development of streptozotocin-induced memory deficit in rats. Drug Res (Stuttg) 2017; 67: 425-431
[163] Sanadgol N, Golab F, Mostafaie A, Mehdizadeh M, Abdollahi M, Sharifzadeh M, Ravan H. Ellagic acid ameliorates cuprizone-induced acute CNS inflammation via restriction of microgliosis and down-regulation of CCL2 and CCL3 pro-inflammatory chemokines. Cell Mol Biol (Noisy-le-grand) 2016; 62: 24-30

[164] Nejad KH, Dianat M, Sarkaki A, Naseri MK, Badavi M, Farbood Y. Ellagic acid improves electrocardiogram waves and blood pressure against global cerebral ischemia rat experimental models. Electron Physician 2015; 7: 1153-1162

[165] Nejad KH, Gharib-Naseri MK, Sarkaki A, Dianat M, Badavi M, Farbood Y. Effects of ellagic acid pretreatment on renal functions disturbances induced by global cerebral ischemic-reperfusion in rat. Iran J Basic Med Sci 2017; 20: 75-82

[166] Farbood Y, Sarkaki A, Dolatshahi M, Taqhi Mansouri SM, Khodadadi A. Ellagic acid protects the brain against 6-hydroxydopamine induced neuroinflammation in a rat model of Parkinson's disease. Basic Clin Neurosci 2015; 6: 83-89

[167] Liu QS, Deng R, Li S, Li X, Li K, Kebaituli G, Li X, Liu R. Ellagic acid protects against neuron damage in ischemic stroke through regulating the ratio of Bcl-2/Bax expression. Appl Physiol Nutr Metab 2017; 42: 855-860

[168] Sarkaki A, Farbood Y, Dolatshahi M, Mansouri SM, Khodadadi A. Neuroprotective effects of ellagic acid in a rat model of Parkinson's -disease. Acta Med Iran 2016; 54: 494-502

[169] Baluchnejadmojarad T, Rabiee N, Zabihnejad S, Roghani M. Ellagic acid exerts protective effect in intrastriatal 6-hydroxydopamine rat model of Parkinson's disease: possible involvement of ER $\beta / \mathrm{Nrf} 2 / \mathrm{HO}-1$ signaling. Brain Res 2017; 1662: 23-30

[170] Khatri DK, Juvekar AR. Kinetics of inhibition of monoamine oxidase using curcumin and ellagic acid. Pharmacogn Mag 2016; 12: S116-S120

[171] Keshtzar E, Khodayar MJ, Javadipour M, Ghaffari MA, Bolduc DL, Rezae M. Ellagic acid protects against arsenic toxicity in isolated rat mitochondria possibly through the maintaining of complex II. Hum Exp Toxicol 2016; 35: 1060-1072

[172] Siah M, Farzaei MH, Ashrafi-Kooshk MR, Adibi H, Arab SS, Rashidi MR Khodarahmi R. Inhibition of guinea pig aldehyde oxidase activity by different flavonoid compounds: an in vitro study. Bioorg Chem 2016; 64: $74-84$

[173] Athukuri BL, Neerati P. Enhanced oral bioavailability of metoprolol with gallic acid and ellagic acid in male Wistar rats: involvement of CYP2D6 inhibition. Drug Metab Pers Ther 2016; 31: 229-234

[174] Zhang HM, Zhao L, Li H, Xu H, Chen WW, Tao L. Research progress on the anticarcinogenic actions and mechanisms of ellagic acid. Cancer Biol Med 2014; 11: 92-100

[175] Liang WZ, Chou CT, Cheng JS, Wang JL, Chang HT, Chen IS, Lu T, Yeh JH, Kuo DH, Shieh P, Chen FA, Kuo CC, Jan CR. The effect of the phenol compound ellagic acid on $\mathrm{Ca}^{2+}$ homeostasis and cytotoxicity in liver cells. Eur J Pharmacol 2016; 780: 243-251

[176] Vicinanza R, Zhang Y, Henning SM, Heber D. Pomegranate juice metabolites, ellagic acid and urolithin A, synergistically inhibit androgen-independent prostate cancer cell growth via distinct effects on cell cycle control and apoptosis. Evid Based Complement Alternat Med 2013; 2013: 247504

[177] Wu S, Tian L. Diverse phytochemicals and bioactivities in the ancient fruit and modern functional food pomegranate (Punica granatum). Molecules 2017; 22: 1606

[178] Eskandari E, Heidarian E, Amini SA, Saffari-Chaleshtori J. Evaluating the effects of ellagic acid on pSTAT3, pAKT, and pERK1/2 signaling pathways in prostate cancer PC3 cells. J Cancer Res Ther 2016; 12: 1266 1271

[179] Wang L, Li W, Lin M, Garcia M, Mulholland D, Lilly M, Martins-Green M. Luteolin, ellagic acid and punicic acid are natural products that inhibit prostate cancer metastasis. Carcinogenesis 2014; 35: 2321-2330 
[180] Kowshik J, Giri H, Kishore TK, Kesavan R, Vankudavath RN, Reddy GB, Dixit M, Nagini S. Ellagic acid inhibits VEGF/VEGFR2, PI3K/Akt and MAPK signaling cascades in the hamster cheek pouch carcinogenesis model. Anticancer Agents Med Chem 2014; 14: 1249-1260

[181] Naiki-Ito A, Chewonarin T, Tang M, Pitchakarn P, Kuno T, Ogawa K, Asamoto M, Shirai T, Takahashi S. Ellagic acid, a component of pomegranate fruit juice, suppresses androgen-dependent prostate carcinogenesis via induction of apoptosis. Prostate 2015; 75: 151-160

[182] Núñez-Sánchez MA, Karmokar A, González-Sarrías A, García-Villalba R, Tomás-Barberán FA, García-Conesa MT, Brown K, Espín JC. In vivo relevant mixed urolithins and ellagic acid inhibit phenotypic and molecular colon cancer stem cell features: a new potentiality for ellagitannin metabolites against cancer. Food Chem Toxicol 2016; 92: 8-16

[183] Yousef Al, El-Masry OS, Abdel Mohsen MA. Impact of cellular genetic make-up on colorectal cancer cell lines response to ellagic acid: implications of small interfering RNA. Asian Pac J Cancer Prev 2016; 17: 743748

[184] Zhao J, Li G, Bo W, Zhou Y, Dang S, Wei J, Li X, Liu M. Multiple effects of ellagic acid on human colorectal carcinoma cells identified by gene expression profile analysis. Int J Oncol 2017; 50: 613-621

[185] Yousef Al, El-Masry OS, Yassin EH. The anti-oncogenic influence of ellagic acid on colon cancer cells in leptin-enriched microenvironment. Tumour Biol 2016; 37: 13345-13353

[186] Umesalma S, Nagendraprabhu P, Sudhandiran G. Ellagic acid inhibits proliferation and induced apoptosis via the Akt signalling pathway in HCT-15 colon adenocarcinoma cells. Mol Cell Biochem 2015; 399: 303-313

[187] Syed U, Ganapasam S. Beneficial influence of ellagic acid on biochemical indexes associated with experimentally induced colon carcinogenesis. J Cancer Res Ther 2017; 13: 62-68

[188] Cheng H, Lu C, Tang R, Pan Y, Bao S, Qiu Y, Xie M. Ellagic acid inhibits the proliferation of human pancreatic carcinoma PANC-1 cells in vitro and in vivo. Oncotarget 2017; 8: 12301-12310

[189] Chen HS, Bai MH, Zhang T, Li GD, Liu M. Ellagic acid induces cell cycle arrest and apoptosis through TGF- $\beta /$ Smad3 signaling pathway in human breast cancer MCF-7 cells. Int ] Oncol 2015; 46: 1730-1738

[190] Shi L, Gao X, Li X, Jiang N, Luo F, Gu C, Chen M, Cheng H, Liu P. Ellagic acid enhances the efficacy of PI3K inhibitor GDC-0941 in breast cancer cells. Curr Mol Med 2015; 15: 478-486

[191] Ahire V, Kumar A, Mishra KP, Kulkarni G. Ellagic acid enhances apoptotic sensitivity of breast cancer cells to $\gamma$-radiation. Nutr Cancer 2017; 69: 904-910

[192] Engelke LH, Hamacher A, Proksch P, Kassack MU. Ellagic acid and resveratrol prevent the development of cisplatin resistance in the epithelial ovarian cancer cell line A2780. J Cancer 2016; 7: 353-363

[193] Abdelazeem KNM, Singh Y, Lang F, Salker MS. Negative effect of ellagic acid on cytosolic $\mathrm{pH}$ regulation and glycolytic flux in human endometrial cancer cells. Cell Physiol Biochem 2017; 41: 2374-2382

[194] Guo H, Zhang D, Fu Q. Inhibition of cervical cancer by promoting IGFBP7 expression using ellagic acid from pomegranate peel. Med Sci Monit 2016; 22: 4881-4886

[195] Kumar D, Basu S, Parija L, Rout D, Manna S, Dandapat J, Debata PR. Curcumin and ellagic acid synergistically induce ROS generation, DNA damage, p 53 accumulation and apoptosis in HeLa cervical carcinoma cells. Biomed Pharmacother 2016; 81: 31-37

[196] Ceci C, Tentori L, Atzori MG, Lacal PM, Bonanno E, Scimeca M, Cicconi R, Mattei M, de Martino MG, Vespasiani G, Miano R, Graziani G. Ellagic acid inhibits bladder cancer invasiveness and in vivo tumor growth. Nutrients 2016; 8: E744

[197] Wang D, Chen Q, Liu B, Li Y, Tan Y, Yang B. Ellagic acid inhibits proliferation and induces apoptosis in human glioblastoma cells. Acta Cir Bras 2016; 31: 143-149

[198] Wang D, Chen Q, Tan Y, Liu B, Liu C. Ellagic acid inhibits human glioblastoma growth in vitro and in vivo. Oncol Rep 2017; 37: 1084-1092
[199] Salimi A, Roudkenar MH, Sadeghi L, Mohseni A, Seydi E, Pirahmadi N, Pourahmad J. Ellagic acid, a polyphenolic compound, selectively induces ROS-mediated apoptosis in cancerous B-lymphocytes of CLL patients by directly targeting mitochondria. Redox Biol 2015; 6: 461-471

[200] Mishra S, Vinayak M. Role of ellagic acid in regulation of apoptosis by modulating novel and atypical PKC in lymphoma bearing mice. BMC Complement Altern Med 2015; 15: 281

[201] Wei Y, Wang Y, Xia D, Guo S, Wang F, Zhang X, Gan Y. Thermosensitive liposomal codelivery of HSA-paclitaxel and HSA-ellagic acid complexes for enhanced drug perfusion and efficacy against pancreatic cancer. ACS Appl Mater Interfaces 2017; 9: 25138-25151

[202] Abd-Rabou AA, Ahmed HH. CS-PEG decorated PLGA nano-prototype for delivery of bioactive compounds: a novel approach for induction of apoptosis in HepG2 cell line. Adv Med Sci 2017; 62: 357-367

[203] Dubey A, Park DW, Kwon JE, Jeong Y], Kim T, Kim I, Kang SC, Chi KW. Investigation of the biological and anti-cancer properties of ellagic acid-encapsulated nano-sized metalla-cages. Int J Nanomedicine 2015; 10: $227-240$

[204] Lembo S, Balato A, Di Caprio R, Cirillo T, Giannini V, Gasparri F, Monfrecola $G$. The modulatory effect of ellagic acid and rosmarinic acid on ultraviolet-B-induced cytokine/chemokine gene expression in skin keratinocyte (HaCaT) cells. Biomed Res Int 2014; 2014: 346793

[205] Baccarin T, Lemos-Senna E. Potential application of nanoemulsions for skin delivery of pomegranate peel polyphenols. AAPS PharmSciTech 2017; 18: 3307-3314

[206] Mo J, Kaewnopparat N, Songkro S, Panichayupakaranant P, Reanmongkol W. Physicochemical properties, in vitro release and skin permeation studies of a topical formulation of standardized pomegranate rind extract. Pak J Pharm Sci 2015; 28: 29-36

[207] Mo J, Panichayupakaranant P, Kaewnopparat N, Nitiruangjaras A, Reanmongkol W. Wound healing activities of standardized pomegranate rind extract and its major antioxidant ellagic acid in rat dermal wounds. J Nat Med 2014; 68: 377-386

[208] Junyaprasert VB, Singhsa P, Suksiriworapong J, Chantasart D. Physicochemical properties and skin permeation of Span 60/Tween 60 niosomes of ellagic acid. Int J Pharm 2012; 423: 303-311

[209] Ito S, Wakamatsu K. A convenient screening method to differentiate phenolic skin whitening tyrosinase inhibitors from leukoderma-inducing phenols. J Dermatol Sci 2015; 80: 18-24

[210] Ortiz-Ruíz CV, Berna J, Tudela J, Varon R, García-Cánovas F. Action of ellagic acid on the melanin biosynthesis pathway. J Dermatol Sci 2016; 82: $115-122$

[211] Draelos Z, Dahl A, Yatskayer M, Chen N, Krol Y, Oresajo C. Dyspigmentation, skin physiology, and a novel approach to skin lightening. J Cosmet Dermatol 2013; 12: 247-253

[212] Dahl A, Yatskayer M, Raab S, Oresajo C. Tolerance and efficacy of a product containing ellagic and salicylic acids in reducing hyperpigmentation and dark spots in comparison with $4 \%$ hydroquinone. J Drugs Dermatol 2013; 12: 52-58

[213] Namekata I, Hamaguchi S, Wakasugi Y, Ohhara M, Hirota Y, Tanaka H. Ellagic acid and gingerol, activators of the sarco-endoplasmic reticulum $\mathrm{Ca}^{2}$-ATPase, ameliorate diabetes mellitus-induced diastolic dysfunction in isolated murine ventricular myocardia. Eur J Pharmacol 2013; 706: 48-55

[214] Hemmati AA, Olapour S, Varzi HN, Khodayar M], Dianat M, Mohammadian B, Yaghooti H. Ellagic acid protects against arsenic trioxide-induced cardiotoxicity in rat. Hum Exp Toxicol 2017; 37: 412 419

[215] Lin MC, Yin MC. Preventive effects of ellagic acid against doxorubicininduced cardio-toxicity in mice. Cardiovasc Toxicol 2013; 13: 185-193

[216] Kannan MM, Quine SD, Sangeetha T. Protective efficacy of ellagic acid on glycoproteins, hematological parameters, biochemical changes, and electrolytes in myocardial infarcted rats. J Biochem Mol Toxicol 2012; 26: $270-275$ 
[217] Kannan MM, Quine SD. Ellagic acid inhibits cardiac arrhythmias, hypertrophy and hyperlipidaemia during myocardial infarction in rats. Metabolism 2013; 62: 52-61

[218] Dianat M, Amini N, Badavi M, Farbood Y. Ellagic acid improved arrhythmias induced by $\mathrm{CaCl}_{2}$ in the rat stress model. Avicenna J Phytomed 2015; 5: 120-127

[219] Olgar Y, Ozturk N, Usta C, Puddu PE, Ozdemir S. Ellagic acid reduces Ltype Ca2+ current and contractility through modulation of NO-GCcGMP pathways in rat ventricular myocytes. J Cardiovasc Pharmacol 2014; 64: 567-573

[220] Abuelsaad AS, Mohamed I, Allam G, Al-solumani AA. Antimicrobial and immunomodulating activities of hesperidin and ellagic acid against diarrheic Aeromonas hydrophila in a murine model. Life Sci 2013; 93: 714-722

[221] Park SW, Kwon MJ, Yoo JY, Choi H], Ahn Y]. Antiviral activity and possible mode of action of ellagic acid identified in Lagerstroemia speciosa leaves toward human rhinoviruses. BMC Complement Altern Med 2014; 14: 171

[222] Soh PN, Witkowski B, Olagnier D, Nicolau ML, Garcia-Alvarez MC, Berry $A$, Benoit-Vical $F$. In vitro and in vivo properties of ellagic acid in malaria treatment. Antimicrob Agents Chemother 2009; 53: 1100-1106

[223] Howell AB, D'Souza DH. The pomegranate: effects on bacteria and viruses that influence human health. Evid Based Complement Alternat Med 2013; 2013: 606212

[224] Shaygannia E, Bahmani M, Zamanzad B, Rafieian-Kopaei M. A review study on Punica granatum L. J Evid Based Complementary Altern Med 2016; 21: 221-227

[225] Chinsembu KC. Tuberculosis and nature's pharmacy of putative anti-tuberculosis agents. Acta Trop 2016; 153: 46-56

[226] Tran TT, Kim M, Jang Y, Lee HW, Nguyen HT, Nguyen TN, Park HW, Le Dang Q, Kim JC. Characterization and mechanisms of anti-influenza virus metabolites isolated from the Vietnamese medicinal plant Polygonum chinense. BMC Complement Altern Med 2017; 17: 162

[227] Ajala OS, Jukov A, Ma CM. Hepatitis C virus inhibitory hydrolysable tannins from the fruits of Terminalia chebula. Fitoterapia 2014; 99: 117123

[228] Reddy BU, Mullick R, Kumar A, Sudha G, Srinivasan N, Das S. Small molecule inhibitors of HCV replication from pomegranate. Sci Rep 2014; 4: 5411

[229] Park S, Kim JI, Lee I, Lee S, Hwang MW, Bae JY, Heo J, Kim D, Han SZ, Park MS. Aronia melanocarpa and its components demonstrate antiviral activity against influenza viruses. Biochem Biophys Res Commun 2013; 440: 14-19

[230] Pavlova EL, Zografov NN, Simeonova LS. Comparative study on the antioxidant capacities of synthetic influenza inhibitors and ellagic acid in model systems. Biomed Pharmacother 2016; 83: 755-762

[231] Núñez-Sánchez MA, García-Villalba R, Monedero-Saiz T, GarcíaTalavera NV, Gómez-Sánchez MB, Sánchez-Álvarez C, García-Albert AM, Rodríguez-Gil FJ, Ruiz-Marín M, Pastor-Quirante FA, Martínez-Díaz F, Yáñez-Gascón MJ, González-Sarrías A, Tomás-Barberán FA, Espín JC. Targeted metabolic profiling of pomegranate polyphenols and urolithins in plasma, urine and colon tissues from colorectal cancer patients. Mol Nutr Food Res 2014; 58: 1199-1211

[232] U.S. National Library of Medicine, Clinical Trials.gov. A new supplement for the immune response to HPV infection. NCT02263378. Available at https:/clinicaltrials.gov/ct2/show/results/NCT02263378. Accessed March 16, 2018

[233] U.S. National Library of Medicine, Clinical Trials.gov. Dietary intervention in follicular lymphoma (KLYMF). NCT00455416. Available at https:/clinicaltrials.gov/ct2/show/NCT00455416. Accessed March 16, 2018
[234] U.S. National Library of Medicine, Clinical Trials.gov. Pomegranate extract supplementation in colorectal cancer patients. NCT01916239. Available at https://clinicaltrials.gov/ct2/show/results/NCT01916239. Accessed March 16, 2018

[235] Ertam I, Mutlu B, Unal I, Alper S, Kivçak B, Ozer O. Efficiency of ellagic acid and arbutin in melasma: a randomized, prospective, open-label study. J Dermatol 2008; 35: 570-574

[236] Kasai K, Yoshimura M, Koga T, Arii M, Kawasaki S. Effects of oral administration of ellagic acid-rich pomegranate extract on ultraviolet-induced pigmentation in the human skin. J Nutr Sci Vitaminol (Tokyo) 2006; 52 : 383-388

[237] Aguilar-Zárate P, Wong-Paz JE, Buenrostro-Figueroa J], Ascacio JA Contreras-Esquivel JC, Aguilar CN. Ellagitannins: bioavailability, purification and biotechnological degradation. Mini Rev Med Chem 2017. doi:10.2174/1389557517666170208144742

[238] Lei F, Xing DM, Xiang L, Zhao YN, Wang W, Zhang LJ, Du L]. Pharmacokinetic study of ellagic acid in rat after oral administration of pomegranate leaf extract. J Chromatogr B Analyt Technol Biomed Life Sci 2003; 796: 189-194

[239] Murugan V, Mukherjee K, Maiti K, Mukherjee PK. Enhanced oral bioavailability and antioxidant profiles of ellagic acid by phospholipids. J Agric Food Chem 2009; 57: 4559-4565

[240] Yan L, Yin P, Ma C, Liu Y. Method development and validation for pharmacokinetic and tissue distributions of ellagic acid using ultrahigh performance liquid chromatography-tandem mass spectrometry (UPLC-MS/MS). Molecules 2014; 19: 18923-18935

[241] Seeram NP, Lee R, Heber D. Bioavailability of ellagic acid in human plasma after consumption of ellagitannins from pomegranate (Punica granatum L.) juice. Clin Chim Acta 2004; 348: 63-68

[242] Stoner GD, Sardo C, Apseloff G, Mullet D, Wargo W, Pound V, Singh A Sanders J, Aziz R, Casto B, Sun X. Pharmacokinetics of anthocyanins and ellagic acid in healthy volunteers fed freeze-dried black raspberries daily for 7 days. J Clin Pharmacol 2005; 45: 1153-1164

[243] Lipińska L, Klewicka E, Sojka M. The structure, occurrence and biologica activity of ellagitannins: a general review. Acta Sci Pol Technol Aliment 2014; 13: 289-299

[244] González-Barrio R, Borges G, Mullen W, Crozier A. Bioavailability of anthocyanins and ellagitannins following consumption of raspberries by healthy humans and subjects with an ileostomy. J Agric Food Chem 2010; 58: 3933-3939

[245] Seeram NP, Henning SM, Zhang Y, Suchard M, Li Z, Heber D. Pomegranate juice ellagitannin metabolites are present in human plasma and some persist in urine for up to 48 hours. J Nutr 2006; 136: 2481-2485

[246] Mertens-Talcott SU, Jilma-Stohlawetz P, Rios J, Hingorani L, Derendorf $\mathrm{H}$. Absorption, metabolism, and antioxidant effects of pomegranate (Punica granatum L.) polyphenols after ingestion of a standardized extract in healthy human volunteers. J Agric Food Chem 2006; 54: 89568961

[247] González-Sarrías A, García-Villalba R, Núñez-Sánchez MÁ, ToméCarneiro J, Zafrilla P, Mulero J, Tomás-Barberán FA, Espín JC. Identifying the limits for ellagic acid bioavailability: a crossover pharmacokinetic study in healthy volunteers after consumption of pomegranate extracts. J Funct Foods 2015; 19: 225-235

[248] García-Villalba R, Beltrán D, Espín JC, Selma MV, Tomás-Barberán FA Time course production of urolithins from ellagic acid by human gut microbiota. J Agric Food Chem 2013; 61: 8797-8806

[249] Bayle M, Roques C, Marion B, Audran M, Oiry C, Bressolle-Gomeni FM, Cros G. Development and validation of a liquid chromatography-electrospray ionization-tandem mass spectrometry method for the determination of urolithin $C$ in rat plasma and its application to a pharmacokinetic study. J Pharm Biomed Anal 2016; 131: 33-39 